\title{
Enabled by the past: understanding endogenous innovation in mature industries
}

Ksenia Onufrey

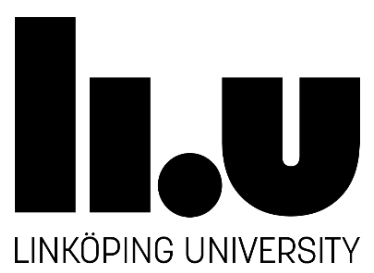

Department of Management and Engineering

Linköping University, Sweden

Linköping 2017 
(C) Ksenia Onufrey, 2017

Published articles have been reprinted with the permission of the copyright holder.

ISBN: 978-91-7685-561-4

ISSN: 0345-7524

Printed in Sweden by LiU-Tryck, Linköping, Sweden, 2017

Distributed by:

Linköping University

Department of Management and Engineering

SE-581 83 Linköping, Sweden

Tel: +4613281000 


\begin{abstract}
Mature industries have played and still play a crucial role in national and world economies. To survive and retain competitiveness, they need to innovate, as innovation is the driver of economics growth and industrial transformation. However, existing research does not provide sufficient explanation of how innovation in mature industries can be enabled based on resources and internal development logic of those industries, i.e. endogenously. Some previous studies focused on incremental innovation patterns, which led to an underestimation of innovation potential of mature industries. Other studies acknowledged a high innovation potential of mature industries, but failed to explain how, through what mechanisms, industry-endogenous logic can bring about major innovations.
\end{abstract}

Therefore, the purpose of this thesis is to systematically address, explain and conceptualize industry-endogenous innovation and its driving mechanisms in mature industries. To achieve this purpose, three main issues are addressed. First, the thesis investigates and conceptualizes the notion of industry endogenous innovation mechanisms based on the path dependency theory. Second, the thesis addresses strategic choices and actions by established companies that are rooted in the industry endogenous mechanisms and result in highly innovative outcomes. Third, the thesis systematically analyses different aspects of radicalness of innovations resulting from industry endogenous mechanisms.

The thesis represents a qualitative, embedded case study with two main industry cases, i.e. the global lighting industry and the Swedish pulp and paper industry. The lighting industry and its subcases in the form of specific lighting technologies have been studied via the analysis of patents of leading lighting manufacturers, archival and secondary data sources as well as interviews with different types of actors in the industry. The pulp and paper industry and its sub-cases in the form of innovation initiatives have been studied with the help of interviews with leading manufacturers and research institutes, as well the analysis of annual reports and secondary data sources. The outcomes of the study are presented in the form of the thesis cover paper and five appended papers.

The results show that innovations of any magnitude can be endogenously developed in mature industries. At the industry level, endogenous innovation is driven by innovation mechanisms that can be conceptualized as reactive sequences and self-reinforcing mechanisms. At the level of individual companies, the exploitation strategy corresponds to the logic of endogenous innovation mechanisms by enabling highly innovative outcomes and building on a wide range of resources available in the industry. The endogenous character of innovation mechanisms imposes certain limitations on the radicalness of the outcomes in the form of trade-offs in terms of how many and what particular aspects can be radically new at once.

With these results, the thesis contributes to a more balanced overall understanding of innovation potential of mature industries and allows shifting the focus of discussion from whether mature industries can develop radical innovation to when and under what conditions they can succeed in this process. The results of the thesis also suggest several recommendations for managers in established companies with regard to how they can they can take advantage of industry endogenous innovation mechanisms.

Keywords: mature industry, endogenous innovation, innovation mechanisms, exploitation, radical innovation, lighting industry, pulp and paper industry. 


\section{Populärvetenskaplig sammanfattning}

Mogna branscher har traditionellt sett spelat och spelar fortfarande en viktig roll för såväl nationella ekonomier som för världsekonomin. För att överleva och behålla sin konkurrenskraft behöver mogna branscher fortsätta vara innovativa, eftersom innovation driver ekonomisk tillväxt. Även för enskilda, etablerade företag i sådana branscher är innovation centralt - de företag som inte lyckas med innovation riskerar att förlora i konkurrensen och bli ersatta av andra.

Det finns emellertid än så länge inte någon bra förklaring till hur innovation i mogna branscher kan möjliggöras endogent, d v s baserat på befintliga resurser och branschens interna utvecklingslogik. Tidigare studier har antingen tenderat att underskatta innovationspotentialen i mogna branscher eller misslyckats med att visa hur - d v s genom vilka mekanismer - branschens egen logik kan möjliggöra radikala innovationer.

Syftet med denna avhandling är att förklara och konceptualisera endogena innovation och dess drivmekanismer i mogna branscher. För att uppnå detta syfte undersöker avhandlingen endogena innovationsprocesser på såväl bransch- som företagsnivå samt analyserar i vilken utsträckning olika aspekter av radikala innovationer möjliggörs av endogena mekanismer.

Avhandlingen är baserad på kvalitativa fallstudier av två branscher. Den första branschen är den globala belysningsindustrin, där olika belysningstekniker har studerats via analyser av patent, sekundära datakällor samt intervjuer med olika typer av aktörer i branschen. Den andra branschen är svensk pappersmassaindustri, där ett antal olika innovationsinitiativ har studerats framförallt med hjälp av intervjuer med ledande företag och forskningsinstitut.

Avhandlingen består av en kappa och fem bifogade artiklar. Resultaten visar att alla typer av innovationer, inklusive radikala innovationer, kan utvecklas endogent i mogna branscher. På industrinivån drivs denna utveckling av innovationsmekanismer i form av reaktiva sekvenser och självförstärkande mekanismer. På företagsnivån kan processen drivas av en innovationsstrategi som bygger på exploatering av befintliga resurser. Trots att alla aspekter av radikala innovationer kan utvecklas endogent, medför endogena mekanismer emellertid vissa begränsningar i form av kritiska avvägningar när det gäller hur många och vilka aspekter som kan hållas radikala samtidigt.

Med dessa resultat bidrar avhandlingen till en mer balanserad, övergripande förståelse för innovationspotentialen i mogna branscher och medger ett skifte av fokus i vetenskapliga diskussioner från frågan om mogna branscher kan utveckla radikala innovationer till när och under vilka villkor de kan lyckas med denna process. I avhandlingen ges även rekommendationer för ledare i etablerade företag med avseende på hur de kan dra nytta av branschens endogena innovationsmekanismer. 


\section{Acknowledgements}

When I look back at my PhD years, I see an exciting, challenging and for the most part very happy period of my life. Today, when I am finishing my thesis, I would like to express my gratitude to people who helped me through this journey.

First of all, I would like to thank my main supervisor Anna Bergek for combining highest expertise with as high levels of commitment, support and care in her supervision. I cannot imagine a better supervisor for myself. Among many other things, thank you, Anna, for your sharp comments that levelled up whatever text you were reading, for always having time when I needed it and for a great experience of co-authoring papers with you.

I would also like to thank my secondary supervisor Thomas Magnusson for his thoughtful feedback on my articles and kappa. All those times I came to you, Thomas, to discuss small or big issues around the thesis, I ended up with a good advise and more clarity on how to move forward.

Thank you, Christian Berggren, for giving me kind and wise advice throughout all these years and for your valuable feedback on my thesis.

I am also grateful to Fredrik Tell and Magnus Holmén for providing feedback on my licentiate thesis and to Christian Sandström för commenting on the earlier version of my $\mathrm{PhD}$ thesis.

Ingrid and Prae, thank you for your friendship, for all the fikas and talks full of laughter, but also for discussing and eventually helping to solve numerous issues that arose over time.

Benny, Carina, Dag, Filiz, Inessa, Mohammad, Nicolette and all of my colleagues at PIE, thank you for creating a nice working environment. Though writing a $\mathrm{PhD}$ can sometimes seem like a lonely endeavour, you kept me feeling a part of a dynamic and friendly team.

I am also endlessly grateful to my family, for being there in my life. Mom and dad, thank you for your care, support and for always being on my side. Kirill, thank for your love, patience and for always being there for me, no questions asked. None of the happy moments over the past years would have been possible without you. Alice and Daniel, thank you for coming into my life and making me happy every day.

Ksenia Onufrey,

Linköping, March 2017. 
To my grandfather Yuri Onufrey 


\section{Appended papers}

Paper 1

Bergek, Anna, and Ksenia Onufrey. 2014. "Is One Path Enough? Multiple Paths and Path Interaction as an Extension of Path Dependency Theory." Industrial and Corporate Change 23 (5): 1261-1297.

Paper 2

Onufrey, Ksenia, and Anna Bergek. 2015. "Self-Reinforcing Mechanisms in a MultiTechnology Industry: Understanding Sustained Technological Variety in a Context of Path Dependency." Industry and Innovation 22 (6): 523-551.

Paper 3

Onufrey, K., 2016. "Endogenous sources of path generation in a path dependent industry." Technology Analysis \& Strategic Management, published online.

Paper 4

Onufrey, Ksenia and Bergek, Anna. 2017. "Second wind for exploitation: pursuing high degrees of product and process innovativeness in mature industries." Under review in a scientific journal.

Paper 5

Onufrey, Ksenia. 2017. "The role of existing resources in developing exploitation-driven innovations in a mature industry." Under review in a scientific journal. 


\section{Table of Contents}

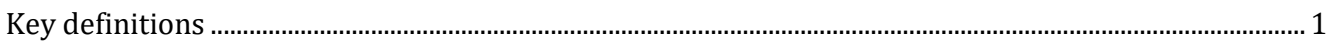

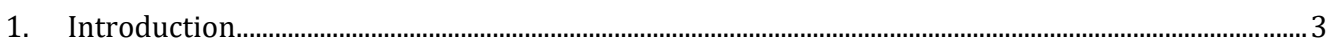

1.1. Background and thesis focus ...................................................................................................... 3

1.2. Established perspectives on innovation in mature industries ..................................................... 4

1.2.1. The perspective focusing on innovation hinders................................................................... 4

1.2.2. The perspective focusing on the possibility of major innovation..........................................

1.3. Problem statement and thesis purpose.................................................................................... 12

1.4. Outline of the thesis and research questions ............................................................................ 13

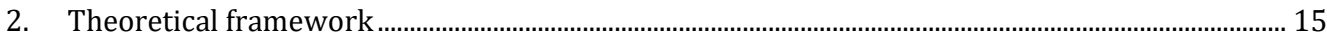

2.1. Defining industry endogenous innovation................................................................................. 15

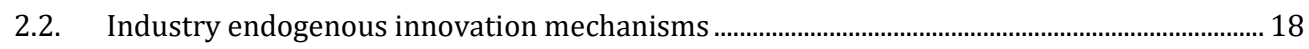

2.3. Industry endogenous innovation mechanisms from the perspective of agency ..................... 23

2.3.1. Company strategies that build upon industry endogenous innovation mechanisms .. 24

2.4. Radical or not?: limits of innovation magnitude set by the endogenous character of

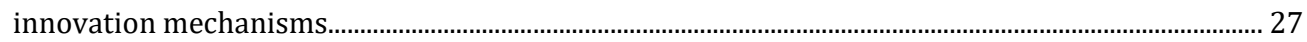

2.5. Summary of the theoretical framework

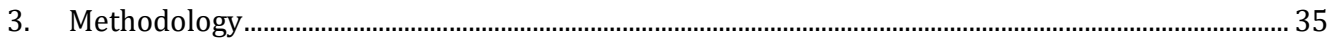

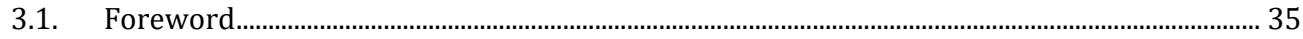

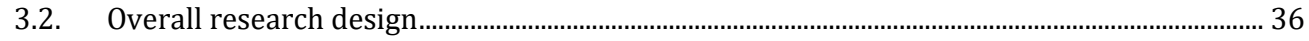

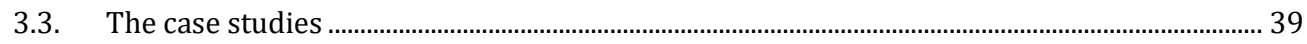

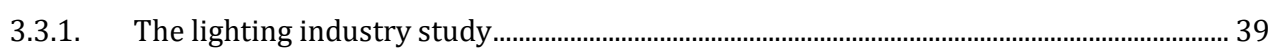

3.3.2. The pulp and paper industry study ………........................................................................... 43

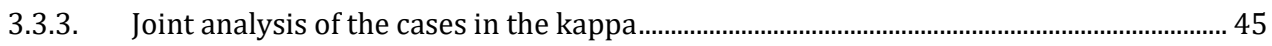

3.4. Reflection on some methodological challenges ........................................................................ 47

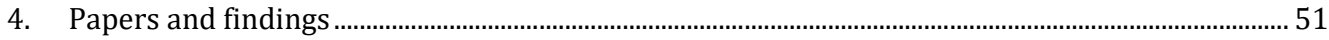

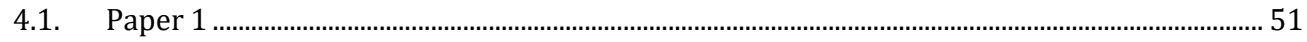

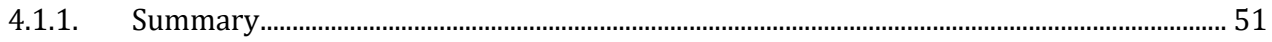

4.1.2. My contribution and publication status................................................................................ 52

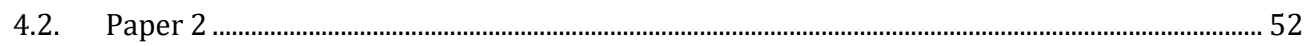

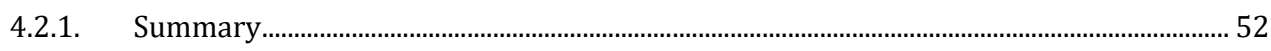

4.2.2. My contribution and publication status........................................................................... 53

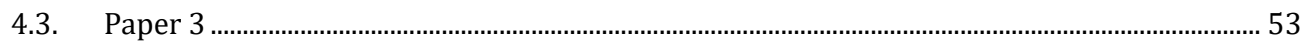

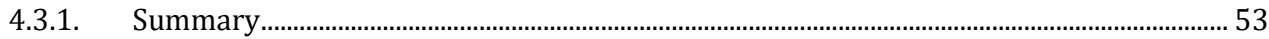


4.3.2. My contribution and publication status................................................................................ 54

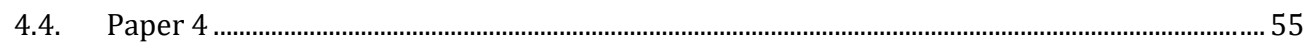

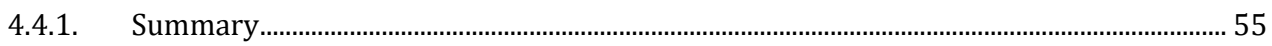

4.4.2. My contribution and publication status.................................................................................. 55

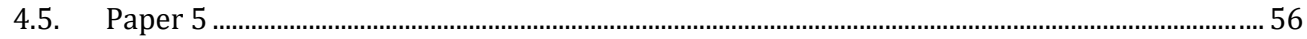

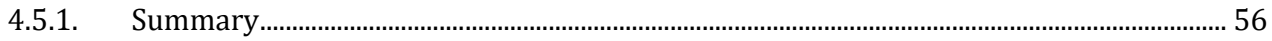

4.5.2. My contribution and publication status................................................................................. 57

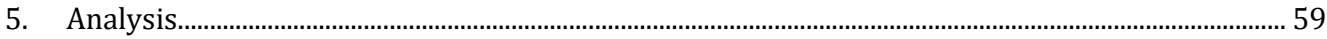

5.1. Reactive sequences and self-reinforcing mechanisms as industry endogenous innovation

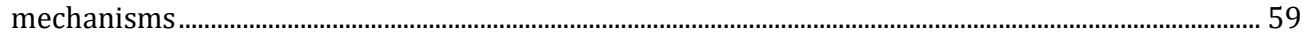

5.2. Company strategies that build upon industry endogenous innovation mechanisms............ 66

5.3. Impact of endogenous innovation mechanisms on the radicalness of outcomes.................... 71

6. Discussion: interconnection between company strategies and industry endogenous innovation

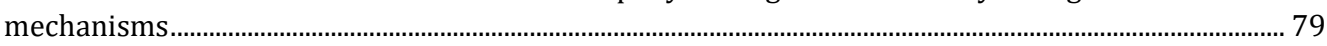

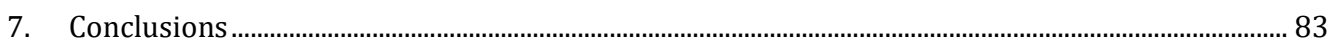

7.1. Contributions and suggestions for future research..................................................................... 84

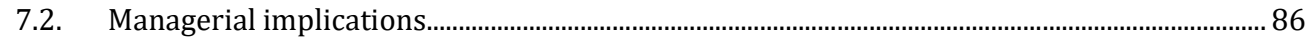

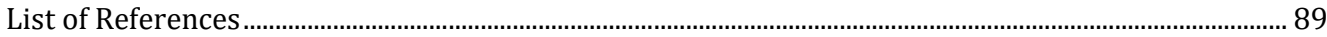




\section{Key definitions}

Incremental innovation - relatively minor changes, improvements and refinements of existing technologies, products or processes that enhance what is accepted as the dominant design in the industry.

Industry - a collection of firms, structures and processes around a particular technology or group of products.

Industry endogenous innovation - innovation building on and driven by resources and development logic of the industry where the innovation takes place.

Industry endogenous innovation mechanisms -a set of forces and cause-effect relationships that are driven by the logic of industry development and lead to innovation of various levels of magnitude.

Mature industry - an industry characterized by a stable structure (in terms of the number of producers and their respective market shares), low entry rates and advanced management, marketing, and manufacturing techniques.

Radical innovation - a product or a technology that is completely new or significantly improved along one or several aspects. In this thesis, "radical innovation" is used as an umbrella term including major innovations, technological discontinuities etc.

Technological innovation - "an iterative process initiated by the perception of a new market and/or new service opportunity for a technology based invention which leads to development, production, and marketing tasks striving for the commercial success of invention" (Garcia and Calantone 2002, p. 112).

Technology - "knowledge applied to products and production processes" (Trott 2008, p. 17). 


\section{Introduction}

\subsection{Background and thesis focus}

This thesis investigates the phenomenon of endogenous innovation in mature industries. Mature industries are distinguished from emerging ones in accordance with the industry life cycle model which characterizes mature industries as having stable structures in terms of the number of producers and their corresponding market shares, low entry rates, as well as advanced and refined management, marketing, and manufacturing techniques (Klepper 1997). Innovation is considered to be industry-endogenous if it builds on the industry's own resources and development logic. Thus, the focus of the thesis is on innovation processes that are rooted in and driven by the logic of evolution of industries that have achieved a mature stage of development.

However, before initiating a more detailed discussion on the nature of such innovation processes as well as on the specifics of mature industries as an innovation context, let us take one step back and ask why the phenomenon of innovation in mature industries is worth studying at all.

The importance of innovation for economic growth and industrial transformation has been accepted since the seminal works by Schumpeter $(1934,1942 / 1994)$. The following decades of research have only strengthened the understanding of the crucial relevance of innovation and technical change for growth and industrial productivity, as well as for international competition and trade (Utterback 1974). From the point of view of wealth creation, companies need to be able to identify and embrace new opportunities (Teece, Pisano et al. 1997). At the same time, innovation is no less crucial for the survival and competitiveness of individual companies (Caiazza 2015). Those companies that fail to take advantage of available new opportunities end up being replaced by those that succeed in this process (Kurkkio 2011).

The relevance of mature industries as an important context for innovation stems from the role they have played and still play in national and world economies. A large number of mature industries are crucial to the economies of many European countries, and many such industries are still growing. Examples include the automotive, aerospace, mechanical engineering, metal producing, paper, pharmaceutical, textile, and wood industries (Castaldi and Sapio 2006). Moreover, studies have shown that firms in mature industries are no less innovative than those in emerging industries (McGahan and Silverman 2001).

However, the existing research does not provide sufficient explanation for the phenomenon of endogenously driven innovation in mature industries. Many previous studies focused on 
incremental innovation patterns, which led to an underestimation of the innovation potential of mature industries (Abernathy and Utterback 1978). Further, those studies that addressed radical innovation in mature industries, failed to explain how-i.e. through what mechanisms-industryendogenous logic can bring about this type of innovation. Therefore, there is a need to better understand endogenous innovation and its underlying mechanisms in mature industries.

To summarize, endogenous innovation in mature industries is an important phenomenon from both theoretical and empirical perspectives. Understanding this phenomenon contributes to clarifying prerequisites for economic growth generally as well as the survival and competitiveness of established firms and mature sectors. However, in spite of the high importance of this phenomenon, there is still no clear understanding of the specific mechanisms and forces that drive endogenous innovation in mature industries. The following sections will take a closer look at the current understanding of these issues in the literature.

\subsection{Established perspectives on innovation in mature industries}

In the literature, two perspectives on innovation in mature industries can be distinguished. One perspective focuses on explaining why mature industries can become less and less innovative over time and therefore addresses the process of developing incremental improvements to already existing technologies and products. The other perspective focuses, conversely, on the situations in which innovations of any magnitude are generated in mature industries. Due to the differences in research focus, the two perspectives highlight different innovation patterns and generate somewhat contradictory conclusions regarding the innovation potential of mature industries. In the following subsections, the reasoning behind both perspectives as well as their implications are discussed.

\subsubsection{The perspective focusing on innovation hinders}

The perspective focusing on innovation hindering forces in mature industries takes its departure from the product and technology life cycle literature1 which argues that the pattern of innovative activities within firms and industries changes over time as a result of a gradually decreasing market and technological uncertainty and a simultaneous increase in product and process standardization (Utterback and Abernathy 1975, Abernathy and Utterback 1978). Anderson and Tushman (1990)

\footnotetext{
1 The initial discussions of product life cycle in Utterback and Abernathy (1975) and Abernathy and Utterback (1978) were further developed into the industry lifecycle approach (cf. Utterback and Suarez 1993, Klepper 1997) where the focus was shifted from the patterns of technology development to the patterns of firm entry and exit in the course of industry development. Since the dynamics of industry entry and exit are outside the scope of this thesis, the discussion in the thesis is limited to the product lifecycle and technology lifecycle literature.
} 
present the process of technology development as a succession of two stages: the era of ferment and the era of incremental change.

The era of ferment is generally characterized by a high rate and magnitude of product innovation as a number of competing product architectures co-exist and develop in parallel. By the end of the era of ferment, a dominant design is established, which is the winning-and later generally adoptedproduct architecture. As the technology (and the associated industry) matures, i.e. as it enters the era of incremental change after the establishment of the dominant design, the innovation environment changes. Technological progress is then mainly driven by a high number of incremental improvements to the dominant design, which serve to elaborate and retain the dominant architecture rather than to challenge it. The development of major product innovations, therefore, becomes less and less likely over time (Anderson and Tushman 1990). When this happens, the forces that limit the rate of product innovation increase: it becomes progressively more difficult to achieve significant improvements of the existing architecture, to alter user loyalty, and there is a tendency towards standardization (Utterback and Abernathy 1975). Thus, innovation activities in mature industries can be described as a succession of small, incremental, and mostly process-oriented improvements, with a focus on economies of scale and price-based competition (Abernathy and Utterback 1978, Brusoni and Sgalari 2006). According to the technology life cycle theory, this low level of innovation activity tends to persist until a new technological discontinuity takes place, followed by a new era of ferment (Anderson and Tushman 1990).

The logic of the industry life cycle reflects the succession between the Schumpeter Mark I and Mark II patterns of innovative activities. The Mark I (also referred to as widening or creative destruction) pattern originates from Schumpeter (1934) and associates innovative activities with new firms and the decline of the technological advantage of established ones. On the other hand, the Mark II (also referred to as deepening or creative accumulation) pattern is based on Schumpeter (1942/1994) and highlights the importance of the innovation activities of large established firms that accumulate technological and innovation capabilities over time (Malerba and Orsenigo 1996). Importantly, the studies referring to those innovation patterns associate the Mark I pattern with the early stage of the technology life cycle and Mark II with the mature stage. This implies that the Mark II innovation pattern follows pre-defined technological trajectories and learning curves. It also adheres to the principle of cumulativeness, which holds that previous knowledge serves as a foundation for future innovation, resulting in incremental, gradual improvements to existing products that remain within the established trajectories (Breschi, Malerba et al. 2000). In the case of major technological or market discontinuities, the Mark II pattern is replaced with the Mark I pattern, which can bring 
radical and disruptive innovation (Galunic and Rodan 1998, Breschi, Malerba et al. 2000). This process can be compared with the beginning of a new technology life cycle.

In line with the overall logic of the technology life cycle, research has also devised complementary lines of explanation for how innovation-hindering forces are formed in mature industries. One of these explanations refers to the tendency of mature industries to be path dependent. Path dependency implies that even distant past choices and events have long-lasting consequences for further development and eventually pre-define future development trajectories (David 1985, Arthur 1989). Path dependent companies and industries are therefore characterized by persistence, i.e. the existence of stable, repeated development patterns (Fai 2003, Sydow, Schreyögg et al. 2009), and self-reinforcing mechanisms, i.e. a development logic that makes initial choices self-sustained and leads to the reproduction of particular development patterns and increasing stability (Mahoney 2000, Araujo and Harrison 2002, Dobusch and Schüssler 2012). Some authors also suggest that path dependent development results in firms being locked-in to existing technologies or products, when only one, often inferior, development alternative remains (Sydow, Schreyögg et al. 2009, Vergne and Durand 2010). Apart from the likely non-optimality of the dominant technology, lock-in also implies that the only remaining source of more radical innovation in mature industries is an exogenous shock that can initiate change by shaking the whole industry setting (Sydow, Schreyögg et al. 2009, Vergne and Durand 2010).

In line with the logic of path dependency and technology life cycle, the strategic management literature suggests that existing resources, accumulated over the course of an industry's development, tend to hinder major innovation. Established companies possess a set of industryspecific core competences, which from the perspective of innovation can turn out to be core rigidities as they significantly limit the magnitude of innovative outcomes (Leonard-Barton 1992). Such a detrimental influence of existing resources on innovation is rooted in the local learning and local search behaviours that encourage companies to look for new solutions in the areas where at least some experience has already been acquired. As a result, established companies tend to close themselves off to more radical alternatives that are based on completely new knowledge bases (Dosi 1982, Rosenkopf and Nerkar 2001, Antonelli 2009). Thus, a reliance on existing resources is viewed by this literature as an obstacle for the development of radical innovation (Nagarajan and Mitchell 1998), or at least the negative consequences of prior experience are believed to be larger than the potential positive ones (Katila and Ahuja 2002). Moreover, the innovation resulting from a reliance on existing resources is considered to be not only of a lower magnitude, but also likely to become obsolete more quickly (Rosenkopf and Nerkar 2001). 
In sum, the technology life cycle logic, path dependent development, and restraining influence of existing resources together provide an explanation for how and why innovation hindering forces arise in mature industries. Although it is not the primary premise of this perspective that mature industries are largely non-innovative, the hindering forces inevitably limit the range of available innovation opportunities, which creates a view of mature industries as having a rather low innovation potential. Indeed, innovation hinders are often cited to explain the no more than incremental innovation in some firms and some of the studies (especially within path dependency research) go as far as claiming that established companies in mature industries are incapable of generating radical innovation (see Table 1). Therefore, established companies are often pictured as being threatened by major breakthroughs introduced by external parties.2 For example, the wellestablished concepts of competence-destroying (Tushman and Anderson 1986) and disruptive innovations (Christensen and Rosenbloom 1995) both imply that established companies are not able to keep up with the new pace and direction of development, either due to the lack of competence, as in the case of competence-destroying innovations, or due to a failure to appreciate the value of new performance attributes, as in the case of disruptive innovations.

\section{Table 1. Literature citations suggesting a low innovation potential of mature industries}

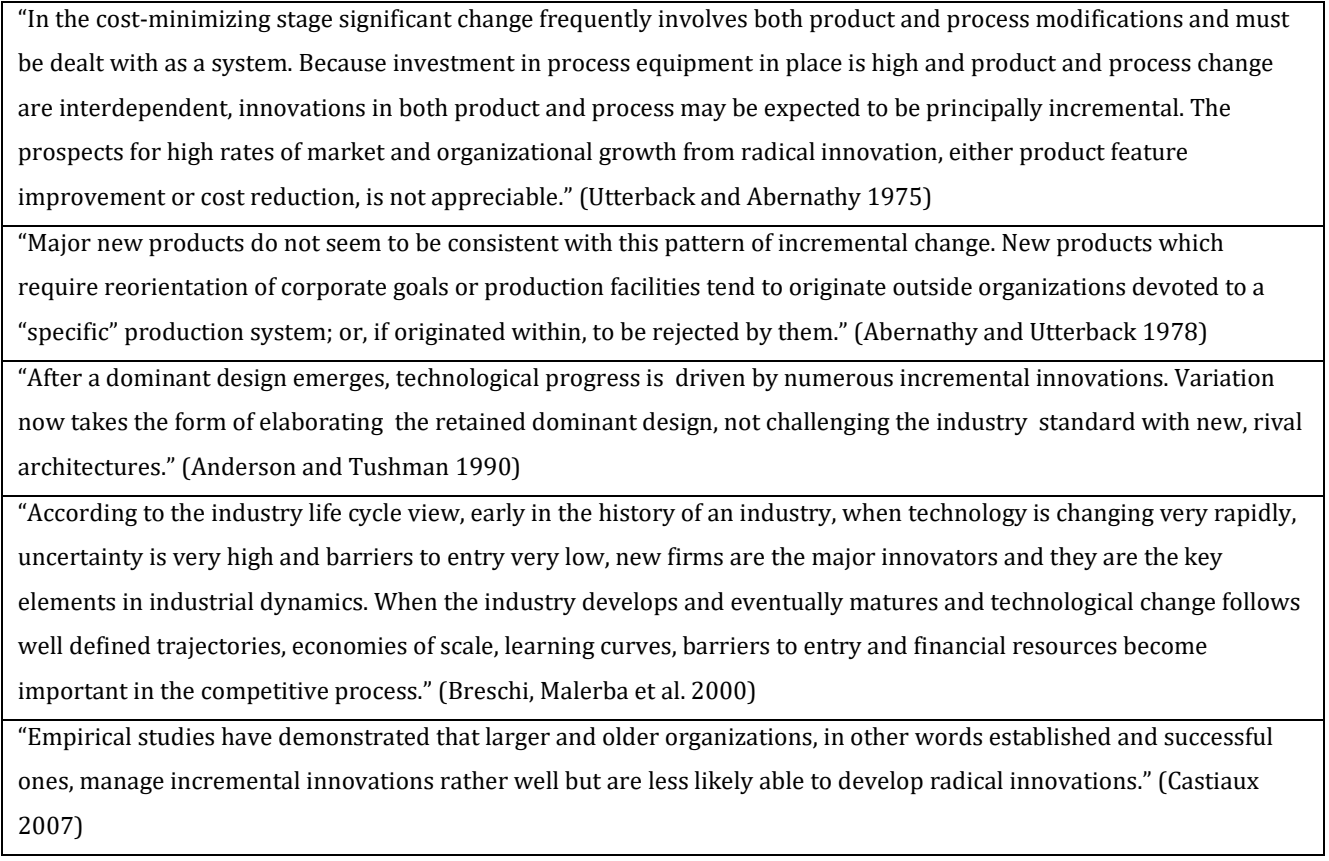

2 Such external breakthroughs can also be compared to exogenous shocks discussed above regarding lock-in. 
"Our position in this paper is that exogenous shocks are required to shake the system free of its history."

"When a process possesses the property of path dependence, then lock-in will occur on one of the possible outcomes if no exogenous shock disturbs the system. Lock-in characterizes a state of equilibrium with a very low potential for endogenous change - put simply, lock-in is a hard-to-escape situation. Path dependence has a true theoretical substance that basically says: when contingently selected paths undergo self-reinforcement, then, ceteris paribus, lockin will occur on one single path as alternative options are selected out (owing to negative externalities). Lock-in is a state of the system that cannot be escaped endogenously." (Vergne and Durand 2010)

As highlighted above, one way to introduce radical innovation in mature industries dominated by innovation-hindering forces is through an exogenous shock that disrupts the development logic that existed before. Another way is for companies to abandon their existing resources and instead strive for new knowledge bases, as well as novel production methods and processes (Methé, Swaminathan et al. 1996, Hill and Rothaermel 2003). In other words, established companies need to break with the past and even cannibalize their previous investments (Herrmann, Tomczak et al. 2006). Interestingly, the studies of technology paths describe a similar option through the concept of path creation, which suggests that companies may "mindfully deviate" from established routines and practices and thereby succeed in initiating change in a path dependent mature industry environment (Garud, Kumaraswamy et al. 2010). It is important to note that aiming for path creation implies a disruption of the logic of existing self-reinforcing mechanisms and therefore is as much "breaking with the past" as the advice given in the strategic management literature discussed above.

All in all, the theories discussed above focus predominantly on innovation-hindering forces and their consequences in mature industries. Therefore, the highest level of innovative outcomes that is discussed in relation to mature industry setting is the level of incremental improvements to already existing products and technologies. Major innovations are considered to be the result of exogenous interventions in the industry development logic, or the result of exceptional actions of established companies aimed at abandoning existing resources and breaking the established development logic. All of that contributes to creating an overall image of mature industries as having a low innovation potential. 


\subsubsection{The perspective focusing on the possibility of major innovation}

In parallel to the research focusing on innovation-hindering forces in mature industries, other (and sometimes closely connected) studies focus on the phenomenon of radical, or major, innovation in mature industries.

Some of the classical studies of technology dynamics do argue that established companies in mature industries can initiate innovation and successfully compete in situations of discontinuous technical change, when the superiority of a new technology is so significant that no improvement of established technologies would make them competitive with the new one (Tushman and Anderson 1986). For example, Tushman and Anderson (1986) argued that competence-enhancing discontinuities are initiated and led by existing firms. While such discontinuities do replace established technologies and products, they still build upon knowledge and skills accumulated in the development of established technologies. A decade later, Christensen and Rosenbloom (1995) further argued that discontinuities of any kind (not only competence-enhancing, but also competence-destroying, i.e. those that build on completely new knowledge bases) can be adopted and driven by existing firms in mature industries. Although these researchers saw other types of hinders for established companies in terms of disruptive innovation, their study acknowledged the capacity of established companies to innovate across both old and new competence bases.

Moreover, the literature that has taken a closer look at the specific role of the resources accumulated by companies over time has produced a number of important arguments in favour of the high innovation potential of mature industries. In contrast to the suggestion that those accumulated resources can hinder or at least limit innovative activities (cf. Leonard-Barton 1992), these studies suggest that previous experience can in fact be a source of competitive advantage when developing new technologies (Cattani 2005). The main argument here is that innovation not only depends on access to new resources, but also on the capability to utilize previously acquired resources (Benner and Tushman 2003). For example, companies can build on some part of their resources (technological or customer competence) in order to get access to and build new resources of other types. This implies that existing resources can contribute to the development of highly novel products and technologies (Danneels 2002). This conceptualization of existing resources as potential innovation drivers has also resulted in recent contributions showing that innovation strategies, focusing on the exploitation of existing knowledge bases and other resources, do not necessarily lead only to incremental innovation outcomes (Li, Vanhaverbeke et al. 2008, Enkel and Gassmann 2010). It should be noted that such findings are in stark contrast to other innovation 
strategy literature that has consistently associated this type of strategy with incremental improvements of existing products and technologies (e.g. Benner and Tushman 2003, Wang and Hsu 2014).

One example of an innovation context in which the role of existing resources is emphasized is the diversification process, i.e. the process whereby established companies innovate beyond their traditional business areas or markets. Some studies of the diversification process have even argued that the widespread underestimation of established companies as sources of radical innovation is due to the previous lack of research attention to the phenomenon of diversified entry (Methé, Swaminathan et al. 1996). The main argument of these studies with regard to the role of existing resources is that the greater the similarity between the resource bases of the companies' old industries and the industries into which they diversify, the more likely the diversification is both to take place and to be successful (Klepper and Simons 2000, Helfat and Lieberman 2002, Thompson 2005). Thus, the studies of technological diversification suggest that relatedness-i.e. the relevance and closeness of the previous knowledge base and other resources-is one of the major drivers of diversification. This in turn implies that companies innovate beyond their traditional markets as a consequence of previous learning (Breschi, Lissoni et al. 2003).

Some of the research discussing the enabling role of existing resources for major innovation in general and for diversification in particular has also raised the question of what specific types of existing resources can be especially valuable for future innovation. Several different answers to this question have been suggested. While some studies distinguished the specific role played by dynamic or second-order capabilities (Teece, Pisano et al. 1997, Danneels 2002), others argued that all kinds of resources and capabilities have the potential to accommodate change due to resources' inherent "fungibility," which allows resource life cycles to extend the life cycles of particular products (Helfat and Peteraf 2003). Yet other studies investigated the value of some specific types of resources and showed that previous production experience (King and Tucci 2002), application-specific knowledge (Sosa 2009), and complementary assets (Teece 1986, Tripsas 1997, Wu, Wan et al. 2014) can play important roles in the process of radical innovation in general and, more specifically, in the diversification of mature industries.

Recent research has continued to make progress in explaining the high innovation potential of established companies in mature industries. One interesting example is the creative accumulation concept put forward to capture the simultaneous processes of new knowledge creation outside the areas of traditional expertise and an intense expansive development of existing knowledge bases 
(Bergek, Berggren et al. 2013). Meeting this challenge proved to be impossible for any companies lacking previous industrial experience, and for established companies to succeed, they needed not only to keep developing their existing technologies while acquiring new knowledge, but also to manage the integration of previously existing and new subsystems (Bergek, Berggren et al. 2013). Other examples of conceptual developments that explain innovation in mature industries include a repositioning of established actors in the socio-technical transitions literature, to underline their ability to enact transitions by changing the course of their development trajectories (Geels 2006), or even to engage in and drive radical innovations in new technology niches instead of focusing merely on defending their established positions (Berggren, Magnusson et al. 2015).

Most of the studies discussed above build on empirical investigations which means that apart from developing conceptual arguments to explain the high innovation potential of mature industries, research has also collected solid empirical evidence for radical innovations that have been introduced by established companies in mature industries. A review of radical innovation over a period of 150 years has shown that many such innovations were introduced by established companies, especially in the second half of the $20^{\text {th }}$ century (Chandy and Tellis 2000). Further, Granstrand and Alänge (1995) argued that over 75\% of innovations (i.e. first commercial introductions of products and processes) in Sweden between 1945 and 1980 across all industrial sectors were introduced by large privately owned corporations, while only $20 \%$ were launched by start-ups. It was also evidenced that among the 100 largest innovations in Swedish history, 47\% were developed by the employees of established corporations (Sandström 2014). Specific examples of mature industries that initiated major innovations at a global scale include airline, cement, microcomputer (Tushman and Anderson 1986), tire manufacturing (Brusoni and Sgalari 2006), gas turbine, automotive power-train (Bergek, Berggren et al. 2013) and heavy vehicle (Berggren, Magnusson et al. 2015), just to name a few.

To summarize, different strands of research have acknowledged and addressed the phenomenon of radical innovation in mature industries. These studies operate with a lot of different conceptual tools and explanations, including, for example, the concepts of competence-enhancing innovations, creative accumulation, innovation strategies, company resources and capabilities. Altogether, they create an alternative, more optimistic view of the innovation potential of mature industries by providing both empirical evidence and theoretical arguments proving that mature industries can and do generate innovation at any level of magnitude. 


\subsection{Problem statement and thesis purpose}

The previous two sub-sections summarized the current understanding of the innovation patterns in and innovation potential of mature industries. The discussion raises several problems.

First, although the two perspectives are not contradictory as such (innovation-hindering forces can and do co-exist with the potential for radical innovation), they do lead to contradictory assumptions about the innovation potential of mature industries. In the first perspective (focusing on innovation hinders), the hindering forces are strongly associated with the innovation pattern dominated by incremental improvements, raising the question of whether there is any room left for flexibility and the possibility for radical innovation. At the same time, in its present form, the second perspective (focusing on a possibility of major innovations) is not systematic enough to counterbalance the first one. Although a number of important arguments allowing for the possibility of major innovation have been gathered by different studies, those arguments are still rather scattered, and, what is more, the studies belong to widely differing levels of analysis and operate with different sets of concepts and terms. Therefore, the view of mature industries as having a low innovation potential remains largely dominant, even though it cannot explain the range of empirical phenomena that involve major innovation.

Second, one particular issue regarding the lack of systematization of the second perspective is that it does not propose any specific mechanisms that would explain how radical innovation can be endogenously enabled, i.e. how radical innovation can be a logical outcome of previous development in a mature industry (for a more elaborate discussion of the term endogenous innovation, see Section 2.1). Whereas the first perspective justifies and explains the forces and mechanisms leading to incremental innovation patterns, the second perspective operates with a number of concepts that support innovation—such as competences, resources, and capabilities—but lacks a conceptualization and explanation of the driving forces and mechanisms behind this process. The reviewed literature mentions the "positive influence," "enabling role," and "leveraging of" existing resources that all have a positive effect on innovation. However, it remains unclear how endogenous innovation might be enabled in mature industries and what kind of logic or causal mechanisms might drive that process. Therefore, in order to sharpen the explanation in favour of the high innovation potential of mature industries, these innovation dynamics need to be captured and explained. 
Taking into account the highlighted problems, the purpose of this thesis is to systematically address, explain, and conceptualize industry-endogenous innovation and its driving mechanisms in mature industries.

The resulting improved understanding of the logic behind endogenous innovation and an overall higher systematization of the arguments in favour of the possibility of major innovations in mature industries will not only contribute to the strengthening of the second perspective, but also allow for a more balanced use of both perspectives. For example, it will become possible to assess both innovation-hindering and enabling forces and to understand to what extent the combination of both sets of forces affects the innovation potential of mature industries. In this respect, it is important to note that although the focus of the thesis is on industry endogenous innovation, there is no intention to simply "beat" the arguments put forward by the hinders-focused perspective, but rather to create a more balanced and more detailed overall understanding of the innovation potential of mature industries.

Several delimitations of the thesis can be outlined. First, the thesis addresses innovation processes in mature industries primarily from the perspective of technology development and to a certain extent - technology adoption (see Section 2.1 for a more detailed discussion of the two perspectives). Another relevant aspect with regard to innovation in mature industries is the role of policy. Institutional pressures are often high in mature industries and can be both externally and endogenously driven (cf. Smink, Hekkert et al. 2015). However, addressing the role of policy would require to considerably broaden the scope of the study in terms of types of actors and processes to include into the analysis, which is why this research direction was not pursued within the scope of this thesis. Second, while the thesis studies endogenous innovation in mature industries, it does not make an assumption that the existence of industry endogenous innovation mechanisms makes all innovations in a given industry endogenous. It is possible that in parallel with endogenous innovations there can appear innovations that are driven by other forces than the internal development logic of the industry.

\subsection{Outline of the thesis and research questions}

Section 2 develops a theoretical framework for discussing endogenous innovation in mature industries. It elaborates the definition of industry endogenous innovation and introduces the concept of industry endogenous innovation mechanisms. Further analysis suggests a framework for conceptualizing and studying these mechanisms based on the path dependency theory and, more specifically, the notions of self-reinforcing mechanisms and reactive sequences. The following 
discussion considers the characteristics of company strategies that correspond to the logic of industry endogenous innovation mechanisms. The suggested characteristics are the use of a broad range of resources available in the industry and the potential to enable highly innovative outcomes. Finally, the theoretical framework critically investigates the magnitude of newness and different types of radicalness that can characterize the innovation enabled by industry endogenous mechanisms. In the course of the theoretical analysis, the following research questions are derived:

RQ1. What industry endogenous mechanisms can enable and sustain innovation in mature industries, and what is the role of self-reinforcing mechanisms and reactive sequences in this process?

RQ2. How can exploitation strategy be used by companies in the context of industry endogenous innovation mechanisms to enable highly innovative outcomes?

RQ3. How do endogenous innovation mechanisms influence the range of radical innovation that can be developed in a mature industry?

Section 3 provides an overview of the research design and a methodological summary of the thesis, and presents two industry case studies (the global lighting industry and the Swedish pulp and paper industry).

Section 4 summarizes five appended papers.

Section 5 analyses the thesis findings and answers the research questions.

Section 6 discusses the interconnection between industry-wide innovation mechanisms and company strategies.

Section 7 concludes the thesis, formulates its main contributions, makes suggestions for future research, and gives the managerial implications. 


\section{Theoretical framework}

\subsection{Defining industry endogenous innovation}

As clarified in the introduction, the focus of this thesis is industry endogenous innovation, which can be broadly understood as innovation that is rooted in and driven by an industry's own development logic. With regard to a more specific definition, it needs to be noted that although the notion of endogenous innovation is referred to in the innovation and technology management literature, it is used in different contexts and applied to different levels of analysis, which is why a single commonly accepted definition of "industry endogenous innovation" is currently lacking. Therefore, in this section, a working definition of the term "industry endogenous innovation" is developed by analysing its constituent parts: "industry," “innovation," "endogenous," and "endogenous innovation."

In this thesis, the term industry is understood as the collection of firms, structures, and processes (R\&D, production, distribution) surrounding a particular technology or a group of products (cf. Porter 1980). Since the focus of the thesis is innovation, specific attention is devoted to those actors and processes involved in the development of new products and new technologies.

As for the term innovation, this thesis focuses on technological innovation and uses the OECD definition: "innovation is an iterative process initiated by the perception of a new market and/or new service opportunity for a technology based invention which leads to development, production, and marketing tasks striving for the commercial success of invention" (Garcia and Calantone 2002, p. 112). There are two main approaches to studying technological change and innovation in industries; namely, the technology development (or supply side) approach, which focuses on activities and resources of companies, and the technology adoption (or demand side) approach, which considers the role of market requirements and customer needs (Christensen and Bower 1996). This thesis takes the technology development approach implying that the logic of technology development is of primary interest, whereas the dynamics of technology diffusion per se are out of the scope of this study. However, previous research has pointed out that technology adoption processes affect the decisions with regard to technology development in companies as well as the overall logic of technology evolution in industries (Adner and Levinthal 2001), which is why market requirements and customer needs will be considered in the thesis factors influencing technology development. However, there is no agreement in the research as to how this influence manifests itself. For example, Christensen and Bower (1996) have argued that the stable needs of existing customers encourage manufacturers to focus on certain performance requirements, which puts 
them at risk of failure in the face of disruptive innovations-i.e. those innovations that are not aligned with the needs of existing customers. As clarified in further studies, the underlying reason for that is not a sudden appreciation of new performance attributes by existing customers, but the fact that the old performance trajectories have become so advanced over the course of technology development that the corresponding performance attributes are satisfied beyond actual requirements, which is why no further improvement along these trajectories can make them more attractive (Adner 2002). Further, Adner and Levinthal (2001) highlight another influence of customer preferences on technology development. They argue that although technology adoption is subject to path dependency, the inherent diversity in customer needs and requirements creates competitive pressures that enable continued innovation and steady rates of product improvements, even at a mature stage of technology development. It needs to be noted though, that such improvements still tend to be of an incremental character. Finally, Tripsas (2008) questioned the established assumption of the adoption perspective that customer needs and preferences are static, arguing that changes in preferences can trigger technological innovation.

Regarding the term endogenous, according to the dictionary, it means "originating, developing or proceeding internally, from within an organism or a system" (TheFreeDictionary 2016). This meaning is, in general, adopted by the innovation and technology management literature, although it is difficult to find a direct explanation of the term. Among the phenomena characterised in the literature as endogenous, one commonly used concept is that of "endogenous growth," which implies that "growth is an endogenous outcome of an economic system" (Romer 1994, p. 3), i.e. the result of research and development that had previously taken place within the particular economic system (Carlsson and Eliasson 2003). Further, Dosi and Nelson (2010) discuss "endogenously accumulated knowledge," which they define as knowledge developed by the same people and organizations who use it. Sandén and Hillman (2011) refer to "endogenous forces" as forces originating in the studied innovation system and governed by the system's internal feedbacks, which implies the crucial role of internal development logic.

There are also several examples of use of the concept of endogenous innovation, applied either at the system level or the company level.s There, company-endogenous innovation is defined as "the process of using an organization's own knowledge assets and capabilities to develop new products and services" (Li, Li et al. 2011, p. 159). As for the system level, a study of endogenous innovation in

\footnotetext{
3 It needs to be noted that most of the examples that use "endogenous innovation" belong to econometric studies where the term "endogenous" has a narrow statistical meaning, i.e. that an explanatory variable is correlated with an error term. Therefore, those studies have been excluded from the present review.
} 
developing countries associates the endogenous character of innovation with the capacity of actors that belong to a country's sectoral system of innovation develop innovations in a particular emerging field, rather than imitate innovations developed somewhere else or apply reverse engineering techniques (McMahon and Thorsteinsdóttir 2013).

As the above examples suggest, for innovation to be considered endogenous, it needs to involve actors and be based on resources that belong to a particular system (e.g. an industry). But even more importantly, endogenous innovation needs to be a logical outcome of previous development in that system. This latter characteristic is crucial for distinguishing endogenous phenomena from non-endogenous ones. For example, some studies operate with the terms "exogenous" or "external" to describe changes induced into a system from the outside (cf. Romer 1994, Dosi and Nelson 2010, Louçã 2014). Thus, some studies of regional innovation processes refer to exogenous factors such as those that do not belong to a particular region (Deniozos 1994, Adams 2011), while a change "exogenous to the industry" is characterised as the one pioneered by industry outsiders rather than by established companies (Arend 1999). However, not all change and innovation processes with external/exogenous origins or connections would eventually disrupt the development logic of an industry (though it is reasonable to assume that endogenous innovation not only follows the industry's development logic, but often also origins within the industry). Therefore, even in cases of change originating outside a particular industry (e.g. if an industry needs to adopt to variation in prices or new policy pressures), it is important to consider whether the response to that external change is still in line with the development logic that previously existed in the industry, or the preexisting logic had to be disrupted. In the former case the adaptation process can be characterised as at least partially endogenously driven, but not in the latter case.

Based on the above, industry endogenous innovation can be defined as a process of new technology or new product development, production, and commercialization that involves established industry actors, is driven by industry's own resources and development logic. Importantly, according to this definition, involvement of industry-established companies is a necessary, but not sufficient condition for an innovation to be industry endogenous. For example, if an established company breaks with the industry's existing resource base or with its established development patterns, the resulting innovation can be considered as internal to the industry, but not industry endogenous. That is because industry endogenous innovation is rooted not only in actors and structures, but also industry processes and its development logic. 


\subsection{Industry endogenous innovation mechanisms4}

In order to achieve a better understanding of industry endogenous innovation in mature industries, it is important to take into account the gaps in the current research. As summarized in the introduction of the thesis, the existing research on endogenous innovation in mature industries is characterized by an insufficient level of systematization and, in particular, the absence of specific mechanisms that would explain how innovation can be enabled in mature industries and what kind of logic drives this process. To handle this, the discussion of industry endogenous innovation needs to provide a conceptualization and an explanation of the specific mechanisms that drive this process. The lack of any conceptualization of endogenous innovation mechanisms stands in stark contrast to the research that belongs to the hinders-focusing perspective on the innovation in mature industries, where mechanisms that hinder innovation are well pronounced and widely used to argue against the possibility of endogenously driven major innovation. For example, the path dependency theory operates with the notion of self-reinforcing mechanisms that systematically bound the magnitude of innovative activities and eventually lead to lock-in.

In order to address this deficiency, this section elaborates the notion of industry endogenous innovation mechanisms. At a more general level, innovation mechanisms correspond to the dynamic forces that bring about and drive innovation. An important component of such mechanisms is the presence of a logic that explains how innovation is initiated and developed and shows a causal relationship between events during the course of development (cf. Mahoney 2000). Therefore, industry endogenous innovation mechanisms can be defined as a set of forces and cause-effect relationships that are driven by the logic of industry development and lead to innovation of various levels of magnitude.

The discussion of industry endogenous innovation mechanisms in this thesis takes its departure from technological path dependency theory. There are two main reasons why this theory provides an appropriate basis for an improved conceptualization of industry endogenous innovation mechanisms. First, as the overview of the hinders-focusing perspective on innovation in mature industries has shown, path dependency theory is one of the main tools used for analysing the development patterns in mature industries. As this thesis does not intend simply to discard the

4 This thesis represents a compilation of five research papers. That is why a part of the theoretical discussion that is included in this and the following sections is based on the theoretical frameworks of the appended papers. For example, the discussion of path dependency and self-reinforcing mechanisms was previously elaborated in the appended papers 1 and 2; path generation was discussed in the appended paper 3; exploitation innovation strategy was investigated in the appended paper 4; the role of existing resources in the innovation process was summarized in the appended paper 5 . 
dominant view, but to expand the overall understanding of innovation potential of mature industries and make it more balanced with regard to the magnitude of potential innovative outcomes, it is reasonable to build this discussion on an established conceptual tool rather than to start from scratch. Second, as highlighted above, the concept of self-reinforcing mechanisms is one of the key building blocks of the path dependency theory and, consequently, well elaborated in previous literature. There is, therefore, a good foundation for investigating other types of mechanisms using the established terminology and proven ways of recognizing and capturing logical relationships between different actions, events, or choices.5

As briefly discussed in the introduction to the thesis, the technological path dependency theory assumes the existence of stable development patterns (i.e. technological persistence) driven by a set of self-sustaining forces (i.e. self-reinforcing mechanisms) based on previous, even very distant, choices and events that predefine the course of future development with a likelihood that increases over time (Sydow, Schreyögg et al. 2009). In particular, an industry can be viewed as path dependent if a long-lasting specialization pattern can be distinguished as well as a chain of causal relationships that enable and sustain this stable pattern (Essletzbichler and Winther 1999, Fai and Von Tunzelmann 2001).

Self-reinforcing mechanisms are a central component of path dependency theory, and therefore the related literature has established a rather clear understanding of what an industry endogenous development mechanism means. At a general level, self-reinforcing mechanisms are characterized by an inherent logic or a momentum of their own (Dosi 1982, Mahoney 2000), and they are also compared with feedback loops (Arthur 1994, Koch, Eisend et al. 2009) and virtuous or vicious circles (Pierson 2000).

More specifically, self-reinforcing mechanisms can be identified through the sequence of technology-related choices over time (Arthur 1989, Cowan and Gunby 1996, Mazzoleni 1997) and via the identification of causal connections that exist between earlier and later choices (Dobusch

\footnotetext{
5 Apart from the path dependency theory, several other frameworks could potentially be used to conceptualize industry endogenous innovation mechanisms. For example, the technological innovation systems (TIS) framework offers a set of functions that influence technology development and diffusion (Bergek et al, 2008), and the concepts of dynamic capabilities (Teece, 1997) and organizational routines (Nelson and Winter 1982) were previously used to capture the dynamic aspects of innovation processes in companies. Those alternative frameworks were not chosen over the mechanisms discussed in the path dependency theory partly due to the advantages of the path dependency theory discussed above and partly because none of the alternatives could be used in its present form (e.g. the TIS functions would need to be adapted for mature industry settings, and the concepts of dynamic capabilities and organizational routines would need to be adjusted to the industry level of analysis).
} 
and Schüssler 2012), i.e. to what extent a step made in a specific direction would make further steps in this direction more probable (Pierson 2000). This kind of detailed and dynamic perspective on industry development patterns allows the explanation of how initial conditions together with later steps along the path lead to a specific development outcome (Dobusch and Kapeller 2013) and thus capture the self-reinforcing forces that have led to pattern reproduction (Mahoney 2000, Araujo and Harrison 2002, Page 2006).

The literature on self-reinforcing mechanisms has also come up with a typology of possible industry endogenous mechanisms that can drive forward the development of an industry. All types of mechanisms can affect both technology adopters (users, buyers) and technology developers (manufacturers). Previous studies of path dependency tended to focus mostly on adoption-related self-reinforcing mechanisms. However, in order to achieve the purpose of this thesis, technology development mechanisms need to be explicitly included and technology adoption mechanisms need to be considered in connection to or as a context of technology development.

With respect to both technology development and technology adoption, four main types of selfreinforcing mechanisms are generally identified:

- Coordination effects, i.e. mechanisms that provide incentives to follow the same line of choices as others (Arthur 1994, Dobusch and Schüssler 2012). For example, direct network effects increase the value of a product as the number of adopters grows (Dobusch and Schüssler 2012), and the implementation of industry-wide norms and standards is beneficial for individual manufacturers (Farrell and Saloner 1985).

- Complementarity effects, i.e. mechanisms that motivate the continued use or development of a technology via the existence of complementary products or processes (Sydow, Schreyögg et al. 2009, Dobusch and Schüssler 2012). For example, the attractiveness of a technology for buyers increases with the availability of spare parts or compatible software and hardware products (Farrell and Saloner 1985, Katz and Shapiro 1985). For manufacturers, complementarity effects may arise from vertically integrated products or the re-use of related knowledge bases and physical assets, such as manufacturing facilities (Teece 1986, Dobusch and Schüssler 2012).

- Expectation effects, i.e. mechanisms that provide incentives to "go along" with others by choosing the same course of actions as one expects others to follow (Arthur 1994, Sydow, Schreyögg et al. 2009, Dobusch and Schüssler 2012). For example, expectation effects are in 
place when users adopt a technology for the sake of social belonging, or when best practices get distributed across companies (Sydow, Schreyögg et al. 2009).

- Investment and learning effects, i.e. mechanisms that provide incentives to continue using resources and knowledge that are specific to a particular technology (Dobusch and Schüssler 2012). For example, users tend to learn and get used to particular technologies (especially in the case of high-tech products) and therefore become less and less likely to switch to alternative solutions (Arthur 1996, Cowan and Gunby 1996), and companies experience sunk costs and "learning-by-doing" effects as the experience of developing a particular technology grows (Arrow 1962, Grant 1991).

As the above overview of self-reinforcing mechanisms shows, they provide a solid and detailed foundation for studying industry-endogenous mechanisms, both in terms of a rigorous understanding of what such mechanisms mean and how they are formed over time, as well as what kind of mechanisms can be encountered in the process of technology development and adoption. Therefore, self-reinforcing mechanisms represent an attractive option for conceptualizing industry endogenous innovation mechanisms.

At the same time, there is a major problem that prevents this concept from being used directly, at least in its present form. That is the association of self-reinforcing mechanisms with a level of innovativeness of path dependent industries that decreases over time. Path dependency theory explains the decreased innovativeness with a reduced range of options available as the result of a chain of self-reinforcing mechanisms (David 1985, Cowan and Gunby 1996). Such a view, based on decreasing alternatives, and especially the lock-in scenario (Vergne and Durand 2010), exclude anything more innovative than incremental improvements from the set of possible outcomes.

However, an overall understanding of self-reinforcing mechanisms as a sequence of events united with an inherent logic and leading to a specific outcome would be also applicable for the case of innovation mechanisms, if the range of possible outcomes included major innovations. Therefore, to accommodate the possibility of mature industries in general, and path dependent industries in particular, being innovative, the concept of self-reinforcing mechanisms needs to be extended to include the development logic that could lead to more innovative outcomes. Such an extended conceptualization may include new types of self-reinforcing mechanisms or provide a new understanding of existing types, or both.

It can be noted that broader streams of path dependency theory—namely, institutional, regional or national path dependency—contain insights for such a wider conceptualization. For example, 
innovation in the form of new regional and national paths has been shown to build on previous paths or at least to develop in partial connection with them (Schienstock 2007, Henning, Stam et al. 2013). Further, institutional studies suggest that combinations, enlargements, and transfers of existing institutional configurations may serve as a source of change in a path dependent environment (Storz 2008). In a similar vein, research suggests that legacies of "paths not taken" (i.e. resources associated with once competitive but now defeated paths) may remain inside the winning path and serve as a potential for the development of alternative paths in the future (Schneiberg 2007). All these studies suggest that innovation can be endogenously enabled in a path dependent context, which also implies that some endogenous innovation mechanisms need to be in place to support this process.

While it seems reasonable to build the conceptualization of endogenous innovation mechanisms using the concept of self-reinforcing mechanisms, as explained and motivated above, one more concept within the path dependency theory deserves attention with regard to this discussion; namely, the concept of reactive sequences. Reactive sequences are defined as chains of interconnected events where the outcome logically follows from previous events, but does not reinforce them (Mahoney 2000, Araujo and Harrison 2002). Reactive sequences are a complementary type of endogenously driven mechanisms in path dependent environments. The literature has not yet focused in detail on the innovation potential of reactive sequences (the concept is rather secondary and therefore less elaborated in the path dependency theory), but the possibility for reactive sequences to transform, redirect or reverse existing paths has been previously mentioned (Mahoney 2000, Araujo and Harrison 2002).

In summary, the path dependency literature provides rich ground for discussing industry endogenous innovation mechanisms, primarily via the concept of self-reinforcing mechanisms and potentially also via the concept of reactive sequences. The current perspective of technological path dependency as leading to gradually decreasing levels of innovativeness is a major obstacle for conceptualizing endogenous innovation mechanisms as a part of technological path dependency theory in its present form. However, there are still some hints in the broader path dependency literature implying the existence of such mechanisms in a context of path dependency. Therefore, an extension and further elaboration of the concepts of self-reinforcing mechanisms and reactive sequences is needed in order to incorporate the notion of endogenous innovation mechanisms into technological path dependency theory. To achieve this, an empirical study is needed where innovation processes are considered through the lens of the path dependency concept. 
Taking into account the above discussion, the first research question of the thesis can be formulated as follows:

RQ1. What industry endogenous mechanisms can enable and sustain innovation in mature industries, and what is the role of self-reinforcing mechanisms and reactive sequences in this process?

\subsection{Industry endogenous innovation mechanisms from the perspective of agency}

Most of the technological path dependency literature addresses the various phenomena related to technological development at the overall industry level. In that context, self-reinforcing mechanisms are a set of forces that affect all of the involved companies, irrespective of the differences between them. Furthermore, the companies themselves are not visible in that conceptualization as they are expected to follow the self-reinforcing mechanisms. They are, thus, presented as rather passive in the path dependency theory.

Because of the propensity of path dependency theory to underestimate the role of companies, the concept of "path creation" has been introduced (Garud, Kumaraswamy et al. 2010). The proponents of path creation suggest that companies have a crucial role in driving the course of technological development as they can "mindfully deviate" from established practices and routines (Karnøe and Garud 2000). This discussion shifts the focus from self-reinforcing mechanisms and lock-in as a potential end point of the development process, towards the choices of and interactions between companies that can manipulate self-reinforcing mechanisms and thus view lock-in as a stabilized stage of development rather than an end point (Stack and Gartland 2003, Garud, Kumaraswamy et al. 2010). Thus, agency is the central component of path creation, particularly the will and ability of companies to break the established logic of self-reinforcing mechanisms in order to introduce innovations and prevent lock-in.

This actualization and problematization of the notion of agency in the context of path dependency has some advantages as well as downsides. On the one hand, it was an important step in itself to demonstrate the role of companies in a path dependent system. Moreover, a company's ability to deviate from established practices and to be innovative in spite of self-reinforcing mechanisms was a way to include internally driven innovations in discussions of path dependency. In contrast to exogenous shocks that were previously considered as the only source of change in a path dependent system (Sydow, Schreyögg et al. 2009, Vergne and Durand 2010), innovations introduced as a result of interventions by established actors are rooted inside the industry. On the other hand, such innovations aim to break the logic of self-reinforcing mechanisms and are, therefore, not fully industry endogenous, although they can be considered as industry-internal. Such path-breaking 
innovations, though driven by established actors, lack one important aspect of endogenously driven innovation; namely, a development logic that results from self-reinforcing mechanisms or other endogenous innovation mechanisms.

In summary, the mainstream path dependency literature has neglected the role of companies, and the concept of path creation has focused on the ability of individual companies to interrupt the logic of self-reinforcing mechanisms. None of these two literature streams has so far paid attention to the endogenous innovation mechanisms from the perspective of companies. This implies that the existing literature has not considered an alternative where companies would strategically (consciously and actively) follow the logic of self-reinforcing mechanisms and still manage to be innovative. The main argument of this thesis is that an industry endogenous logic is able to bring about innovations. Therefore, the corresponding strategic actions by companies need to be captured and conceptualized.

Understanding industry endogenous innovation mechanisms from the perspective of company strategies involves investigating the content of such strategies-i.e. the kind of strategic actions and choices that would follow the logic of existing innovation mechanisms and still result in innovation. The following sub-section takes a closer look at the current understanding of such strategies and outlines some remaining gaps.

\subsubsection{Company strategies that build upon industry endogenous innovation mechanisms} In the innovation strategy literature, the strategy that allows companies to build on previously accumulated knowledge and experience is the exploitation strategy. In contrast to exploration that refers to the use of new knowledge bases in the search of new opportunities, exploitation implies "the refinement and extension of existing competences, technologies and paradigms" (March 1991, p. 85). Thus, innovative outcomes are achieved by exploiting the set of available resources that are under the control of the firm (Rothaermel and Deeds 2004).

This description of exploitation innovation strategy is in line with the idea of industry endogenous innovation mechanisms since innovations resulting from exploitation arise from the accumulation of previous experience. Therefore, it can be suggested that exploitation represents the type of strategic action that follows the logic of and builds upon industry endogenous mechanisms. However, in order to claim that, several issues with regard to the content and outcomes of the exploitation strategy need to be further investigated and clarified. With regard to the content of the exploitation strategy, it is not yet clear what kind of resources are to be used and in what way they are to be exploited in the context of industry endogenous innovation mechanisms. As for the 
outcomes of the strategy, the research has not yet reached an agreement about whether exploitation can result in radical innovation. Both these issues are discussed in more detail below.

Company resources and their value in the innovation process are the central themes in the resource-based view of the firm. In a seminal article, Barney (1991) distinguishes between physical, human, and organizational capital resources. Physical capital resources are plants, equipment, raw materials and other material resources. Human capital resources (or competences) include expertise, training and experience of company employees. Finally, organizational resources are organizational structures, relations between groups, formal and informal organizational processes and routines. Based on this categorization, it is easy to assume that exploitation refers to the range of resources that are under the direct control of the firm.

However, such understanding of existing resources does not fully correspond to the variety of resources that are involved in industry endogenous mechanisms. Indeed, the discussion of different types of self-reinforcing mechanisms has shown that they refer to processes that affect not only company-specific resources, but also more general industry attributes. To get an idea of what additional types of resources can potentially be included in the notion of resource exploitation, all types of self-reinforcing mechanisms are considered below from the perspective of the resources involved.

- Coordination effects for manufacturers, among other things, involve following industry norms and standards which form a shared resource across all actors in an industry, but can still be strategically used by individual companies. From an adoption point of view, adopters' preferences and needs can be added to the list of such shared resources. (Moreover, since adopters' preferences are a cornerstone of all adoption-related mechanisms, this resource is valid for all four general types of self-reinforcing mechanisms.)

- Complementarity effects build on a wide range of company-controlled resources, such as related products, related knowledge bases, manufacturing facilities, and distribution channels. However, in the case of distributed supply chains, products can be a result of joint efforts between several different companies. In that case, inter-company relations (e.g. collaborations with suppliers, customers, and other partners) become a relevant resource to consider and to take advantage of. Although companies' network relations are formally a part of their organizational attributes, in accordance with Barney's (1991) categorization, this type of resource can easily become overshadowed by internal organizational attributes and therefore receive less attention. 
- Expectation effects involve company-controlled organizational resources such as company reputation, but also, less explicit in resource discussions, more general attributes of products and technologies (rather than of companies themselves), such as technology legitimacy or reputation of a product.

- Investment and learning effects build partly on company-specific resources that are well described in resource-based literature, such as technology and market competences (e.g. accumulated through learning-by-doing) and organizational routines adapted to current products. At the same time, there are also overarching learning effects that concern the technology field as a whole and reflect the learning that has taken place at an industry-wide level. Thus, a part of knowledge development takes place outside individual companies (e.g. in research institutes) (Bergek, Jacobsson et al. 2008), and technology S-curves are traditionally discussed at the overall industry level (Christensen 1992). From the adoption perspective, a list of relevant resources can be complemented with adopters' competences (in addition to the preferences and needs mentioned above).

Overall, it can be seen that different self-reinforcing mechanisms involve both "traditional" resource types, i.e. those that are generally implied when resource exploitation is discussed, but also a number of additional resources that tend to receive less attention. Some examples of these include resourcess shared across companies, adopters' preferences, needs and competences,6 more general attributes of technologies and products, and companies' network relationships. Therefore, in order to understand how the exploitation strategy can be implemented under the context of industry endogenous innovation mechanisms, the possibility of using an expanded range of resources needs to be allowed. However, an empirical study is needed to investigate what particular resource types are in fact exploited by companies in an industry driven by endogenous innovation mechanisms. Further, since "non-traditional" resources are not under the direct control of companies, special attention needs to be devoted to how and in what way exploitation of those resources can be realized.

With regard to the innovation outcomes of a company strategy that is in line with industry endogenous innovation mechanisms, it is essential that such a strategy is able to bring about major innovations. However, the current research associates exploitation mostly with incremental improvements rather than major innovative outcomes (Benner and Tushman 2003, Bauer and

\footnotetext{
6 Although adopters' preferences, needs and competences can be included in the category of resources that are shared across companies, they are distinguished in a separate category in order to render explicit the role of adoption-related aspects for technology development.
} 
Leker 2013). Although some of the innovation strategy studies have started challenging this assumption by showing a higher innovative potential of exploitation (Li, Vanhaverbeke et al. 2008, Enkel and Gassmann 2010), it is still necessary to demonstrate empirically that exploitation can result in major innovations. One way to do this is to provide evidence that innovations at the company level can appear as the logical outcome of exploitation, just as innovations at the industry level are the logical outcome of industry endogenous mechanisms. Therefore, the causal effects of exploitation need to be captured at the company level by showing the existence of an enabling logic from resource exploitation to highly innovative outcomes. Such an enabling logic would suggest that innovations are developed due to or as a result of resource exploitation and not just as a coincidence alongside exploitation and certainly not in spite of it. Evidence of an enabling logic is therefore a prerequisite for claiming that exploitation can contribute to major innovations and build upon the logic of industry endogenous innovation mechanisms.

To summarize the above discussion, the path dependency theory lacks a framework that would incorporate strategic efforts by companies that are rooted in industry endogenous innovation mechanisms and can result in highly innovative outcomes. The resource exploitation innovation strategy can potentially be viewed as such a strategic effort. However, it remains unclear, first, what kind of resources and in what way can be exploited by companies in the context of industry endogenous innovation mechanisms, and second, whether exploitation strategy can enable highly innovative outcomes. Therefore, the second research question of the thesis is the following:

RQ2. How can exploitation strategy be used by companies in the context of industry endogenous innovation mechanisms to enable highly innovative outcomes?

\subsection{Radical or not?: limits of innovation magnitude set by the endogenous character of innovation mechanisms}

In most of the path dependency literature, as well as so far in this thesis, the innovation potential of mature industries has been discussed using a dichotomy between two extremes, i.e. low vs high innovation potential or incremental vs radical innovative outcomes. This thesis argues that due to the existence of industry endogenous innovation mechanisms, the established companies in mature industries are capable of more-than-incremental innovations and a high innovation level can be achieved even in the absence of external shocks or interventions that break the logic of industry development. Part of the improved understanding of endogenously driven innovation is a clarification of what type of high-level innovation can be achieved due to endogenous mechanisms and, in contrast, what kind of innovations are not likely to be developed endogenously. 
Therefore, a more fine-grained explanation of what kind of innovation can be expected due to industry endogenous innovation mechanisms and what exactly high innovation potential and radical innovation can imply in that case, needs to be developed.

Existing literature offers a variety of innovation typologies that are more detailed than a dichotomy and contain up to eight levels of newness (Garcia and Calantone 2002). However, those typologies are difficult to compare as they use different terminology, definitions, and measurements, and even study different phenomena. Having compared various definitions of radical (or discontinuous) innovation, Ehrnberg (1995) highlighted a great variety in what exactly it is that undergoes a radical change in the different typologies. That inconsistency can be briefly illustrated with an example of disagreement between some of the existing interpretations of radicalness.

In one of the classical innovation studies, Tushman and Anderson (1986) defined a discontinuous innovation as a significant advance in price-performance that makes it impossible for previous technologies to compete. They further distinguished between competence-enhancing discontinuities, which build on existing know-how within an industry, and competence-destroying discontinuities, which build on completely knew knowledge bases and therefore make an existing know-how obsolete. As a result, competence-enhancing discontinuities were positioned as the ones driven by established firms, whereas competence-destroying ones were associated with a threat to established companies. However, another well-known study by Christensen and Rosenbloom (1995) argued against previous authors, showing that competence-destroying discontinuities can actually be successfully handled by established firms. Instead they suggested the notion of disruptive innovation, which involves a new set of performance criteria and, in contrast to all other types of innovation, is threatening for established firms. To make it even more complicated, recent studies of creative accumulation have shown that in some cases disruptive innovations can also be successfully handled by established firms (Bergek, Berggren et al. 2013).

This example shows that careful attention needs to be paid to what exactly different authors consider to be radically new in different categorizations. Whereas Tushman and Anderson (1986) referred to technological competences, Christensen and Rosenbloom (1995) discussed value networks and performance trajectories. With regard to the issues studied in this section, i.e. understanding what particular innovation levels and types can and cannot be developed due to industry endogenous mechanisms, the existence of a variety of aspects through which radicalness can be defined, implies that a comprehensive and integrated overview of different aspects of radicalness is needed. 
To provide such an overview, a summary of radicalness aspects gathered by Ehrnberg (1995) is used as a starting point and further expanded. Ehrnberg (1995) suggested that the various definitions that describe a radical (or discontinuous) innovation can be divided into three groups according to the central aspects highlighted. Those three aspects of radicalness are changes in competences and other resources, changes in physical product or process, and changes in priceperformance level.

With regard to competences and other resources, Ehrnberg (1995) puts her main emphasis on technological competences, while other authors highlight a distinction between two groups of competences, i.e. technological and market competences (Danneels 2002). Radically new technological competences require completely different scientific and engineering knowledge bases (Henderson and Clark 1990), and market novelty refers to a new utility for customers (Herrmann, Tomczak et al. 2006). In addition, as the discussion in the above sections of the thesis highlighted, "other resources," either directly controlled or otherwise managed by companies, involve a wide range of physical and intangible resources, organizational characteristics and technological attributes. It can seem overly complicated to include each resource type in the discussion of different aspects of radicalness of innovations, but it is important to at least distinguish a group of other resources (apart from technological and market competences) as a relevant aspect of radical change.

As for the second overall aspect of radicalness-product and process characteristics-some studies capture the degree to which a physical product itself has been changed (for example, new design, new components or subsystems) (Ehrnberg 1995), while others define radical innovations in terms of the newness of a production process (Garcia and Calantone 2002). This latter parameter is especially important for process industries (which mature industries often are), where the possibilities for product innovation are highly dependent on the flexibility of the production process and where industry complexity is primarily associated with the production process rather than with product architectures (as in assembly industries) (Linton and Walsh 2008, Frishammar, Lichtenthaler et al. 2012).

Finally, within the price-performance aspect, a distinction can be made between studies that consider radical price-performance improvements along with existing performance criteria (e.g., Tushman and Anderson 1986) and those that refer to the introduction of completely new performance criteria (e.g., Christensen and Rosenbloom 1995). Importantly for this group of aspects, the technology adoption perspective is especially relevant, taking into account that the 
influence of the market on technology development is realized through maintenance or change of performance criteria.

Since the focus of the thesis is industry endogenous innovation, for all of the above aspects radicalness is considered from the perspective of a focal industry. It is possible, for example, that certain competences or other resources previously existed in other industries or some performance criteria were already relevant for other technologies. It is the first appearance of those resources and performance criteria in a given mature industry that marks radical innovation in that industry.

The resulting range of different aspects of innovation radicalness can be seen in Figure 1. Importantly, research often refers not only to a complete and full newness according to different aspects as a prerequisite for radical innovation, but also to combinations between old and new characteristics. This is most often mentioned with regard to technological competences (Methé, Swaminathan et al. 1996, Hill and Rothaermel 2003), but it is also highly relevant from the perspective of combinations across different aspects, i.e. combinations of retained characteristics in some aspects and newness in others. For example, an innovation can be radical with regard to technological knowledge, but incremental with regard to production processes. Alternatively, radically new performance can be delivered to the same market (cf. Murmann and Koen 2002). The "and/or-dilemma", i.e. the question of whether an innovation needs to be completely new along all the aspects or just one or some of them in order to be considered radical is unresolved in the innovation literature. While several studies explicitly mention the need for an innovation to be novel both in terms of, e.g. market and technology (e.g. Herrmann, Tomczak et al. 2006), others accept the possibility of newness only along some aspects (Ehrnberg 1995). This thesis sides with the latter standpoint, suggesting that at least one of the established aspects of radicalness should be substantially new for an innovation to be considered radical. 


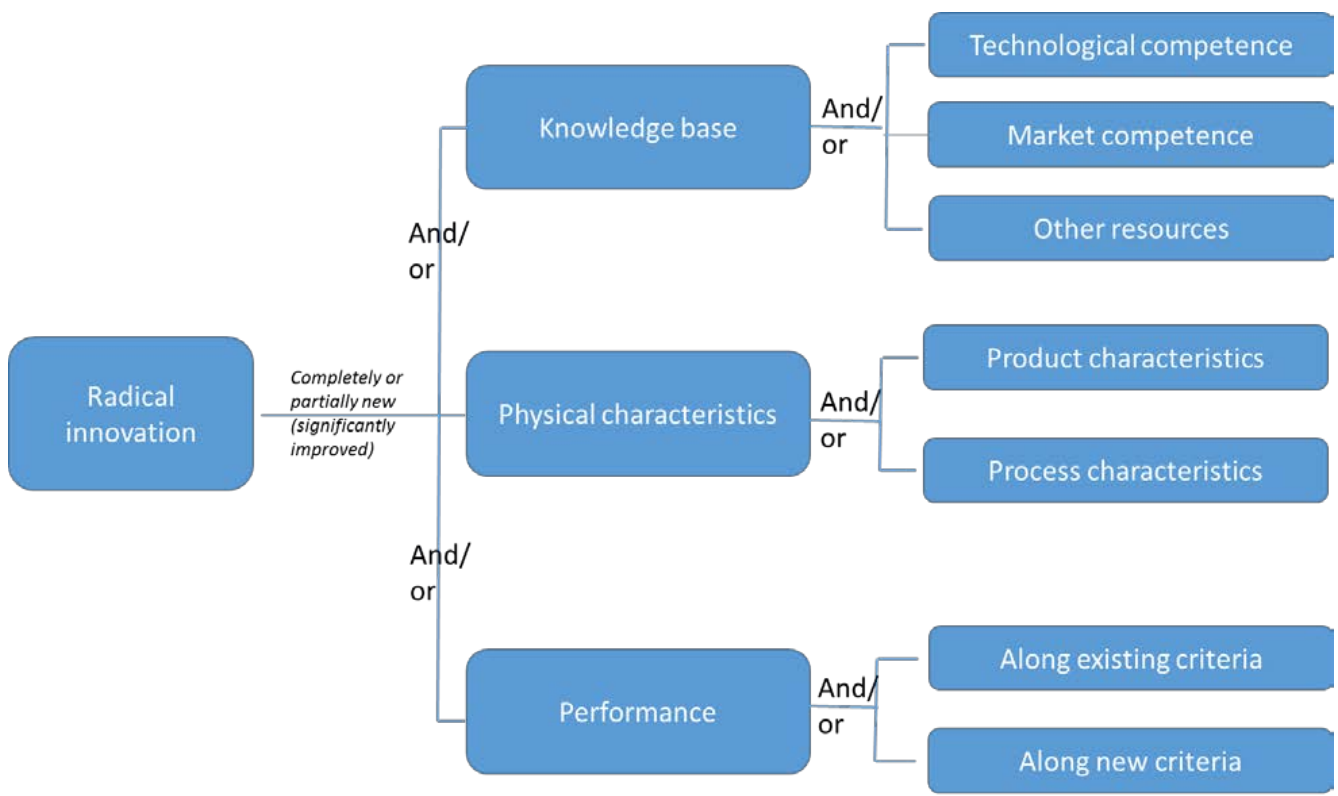

Figure 1. Radicalness of innovation: a range of aspects

This perspective on radical innovations is also in line with the understanding of industry endogenous innovation mechanisms. The endogenous character of innovation mechanisms implies that, while some novel aspects are developed, some other aspects have to be retained and serve as a ground for indigeneity. This would not be possible for innovations that were radical along all aspects. Therefore, it is probably safe to assume that extremely radical innovations, which are completely new in all of the above mentioned aspects, cannot be endogenously driven in mature industries.

A combination of retained and new aspects opens for the possibility that a radical innovation can be driven by industry endogenous mechanisms, i.e. due to rather than in spite of the retained aspects. For example, a recent study of the electric bus industry showed that established companies were likely to introduce more radical innovations due to the existence of previously accumulated resources (e.g. legitimacy), while newcomers who lacked such resources had to largely adapt to established routines, which resulted in a decreased radicalness of their solutions (Borghei and Magnusson 2016). However, the theoretical possibility that endogenous innovation mechanisms can drive radical innovations needs to be empirically studied in order to see how specific radicalness aspects can be enabled by industry endogenous mechanisms as well as if, and in that case why, 
other aspects are less likely to be endogenously enabled. The evidence that innovations that are radical along any aspect(s) can be driven by industry endogenous mechanisms will already be a contribution to the existing theory. But an insight regarding the higher or lower likelihood of specific endogenously driven aspects (or combinations of aspects) of radical innovations, gained from understanding the logic of industry endogenous mechanisms, would inform both the literature and companies' management regarding implications of industry endogenous innovation.

Against this background, the third research question of the thesis is the following:

RQ3. How do endogenous innovation mechanisms influence the range of radical innovation that can be developed in a mature industry?

\subsection{Summary of the theoretical framework}

This section has elaborated the theoretical framework used to study industry endogenous innovation, i.e. those innovation processes that involve established industry actors, and that originate in and are driven by the industry's own resources and development logic.

Within this field, three more specific areas of research have been considered. First, endogenous innovation mechanisms have been discussed as a way to improve conceptual clarity with regard to industry endogenous innovation. Such mechanisms have been considered from the perspective of the technological path dependency theory and in particular, the concepts of self-reinforcing mechanisms and reactive sequences. Possible extensions of these concepts have been suggested to incorporate the development logic that drives and sustains innovation.

Second, industry endogenous innovation has been considered from the perspective of agency, i.e. strategic choices and actions by established companies that are rooted in the industry endogenous innovation mechanisms and result in highly innovative outcomes. It has been suggested that the exploitation innovation strategy can play this role, although the thesis has also highlighted the need to reconsider the range of resources to exploit as well as the magnitude of innovation outcomes of this strategy.

Finally, the radicalness of innovations that are enabled and driven by industry endogenous mechanisms has been considered in more detail. Based on the existing interpretations of radical innovation in the literature, a range of different aspects of radicalness has been developed in order to further investigate what aspects or combinations of aspects are likely to be radically changed as a result of industry endogenous mechanisms. 
The next section will consider the methodological aspects of the thesis, present and justify the choice of research methods, data sources and analysis techniques used to answer the research questions formulated above. 


\section{Methodology}

\subsection{Foreword}

At the beginning of the research process, the thesis was driven by a broadly defined ambition to better understand the dynamics of innovation in mature industries. Why are some industries more innovative than others? Why do some industries come up with innovation at a mature stage of development, while others keep producing or gradually improving existing technologies and products? As the central study object in these questions is an industry, the first natural step in answering them was to choose a mature and still innovative industry in order to understand what kind of processes take place there to support innovations. Thus, an initial broad research question helped in specifying the kind of industry to focus on (Eisenhardt 1989). Industry age and evidence of innovation developed and introduced after the industry had matured were the two main criteria for choosing the first case industry in the thesis. The global lighting industry was chosen since it is a mature industry, the history of which goes back to the end of the $19^{\text {th }}$ century. Over the course of the industry's development, several new technologies have been developed and commercialized. Moreover, the recent introduction of light-emitting diode (LED) technology has made the discussion of the innovation processes highly relevant in the context of this industry.

The first findings in the study of the lighting industry have revealed that apart from maturity and innovativeness, this industry possesses one more important characteristic that is crucial for innovation processes; namely, it is a multi-technology industry. Multi-technology industries are defined as industries in which several technologies with largely overlapping basic functions, markets, and applications co-exist over extended time periods (Onufrey 2014). It is not uncommon that the specific characteristics of a case provide inspiration for new ideas (Siggelkow 2007), and the discussions in the Papers 1-3, which resulted from the lighting industry study, were adapted to take into account the specifics of multi-technology industries. In spite of this analytical detour, the lighting industry case was still very important in understanding innovation processes in mature industries in general. In particular, in the course of this study I was able to sharpen my understanding of a number of conceptual tools that can be used to study innovation in mature industries as well as of the specific processes that are of most interest. For example, the overall purpose of the thesis gradually narrowed and became more theoretically driven (Eisenhardt and Graebner 2007) as the focus shifted from grasping innovation processes in mature industries to analysing industry endogenous innovation and the specific mechanisms that can enable and sustain this process. 
The decision to add one more case industry was motivated partly by the intention to increase the robustness of the results by grounding them on more varied empirical evidence (Eisenhardt and Graebner 2007), and partly to shift focus to issues that were less clear in the lighting industry case. Since the second industry was chosen after having summarized the results of the first study, the criteria for choosing the industry were more precisely formulated. For example, while the lighting industry was an interesting case for a retrospective study since new technologies had been developed over the course of the whole $20^{\text {th }}$ century, it did not provide an equally good understanding of the individual companies' perspectives and an understanding of their strategies. Therefore, for the second industry it was desirable to study fairly contemporary innovation processes where the focus would be on the companies involved. As a result, the Swedish pulp and paper industry was chosen, where established companies have recently started developing innovative initiatives outside their traditional areas of business.

As this overview shows, this thesis is characterized by an iterative research process where initially broad questions provided direction for research at the early stages of the thesis. Further, all the results gathered on the way served to improve the conceptual clarity with regard to the studied phenomena as well as to sharpen and narrow down the specific empirical evidence that would be focused on in the analysis. As a result, the findings of both case studies provided the foundation for understanding endogenous innovation in mature industries, which includes, on the one hand, industry endogenous innovation mechanisms, and on the other, company strategies that build upon those mechanisms.

\subsection{Overall research design}

This thesis represents a qualitative, embedded case study with two main industry cases, i.e. the global lighting industry and the Swedish pulp and paper industry, and a number of sub-cases within each case, i.e. specific technologies (lighting) and products (pulp and paper).

The global lighting industry develops and produces electric light sources for general lighting purposes. Several lighting technologies, which considerably differ from each other in terms of fundamental principles of light generation, have been developed in the industry over time and coexist today. At the most general level, three main lighting technologies can be distinguished: incandescent lamps, discharge lamps, and LED. Further, the first two technologies can be subdivided into more narrow technology fields, such as halogen lamps within incandescent technology, or linear and compact fluorescent lamps within discharge technology, just to name a few. In this thesis, the whole lighting industry serves as the first main case study, while distinct lighting technologies 
are the sub-cases. Paper 1 studies the three main technologies named above, Paper 2 additionally distinguishes the sub-case of compact fluorescent lamps, and Paper 3 includes the subcase of fluorescent lighting (which includes both linear and compact fluorescent lamps).

The Swedish pulp and paper industry develops and produces forest-based products such as paper pulp, packaging, and paper products. The industry has been traditionally conservative in strategy and reluctant to introduce any major innovations (Novotny and Laestadius 2014). However, recent changes in the global market (increased international competition, decreasing demand in some of the key traditional segments) together with the policy-driven call for a transition towards a biobased economy have motivated established producers in the Swedish pulp and paper industry to undertake innovation initiatives outside their traditional business areas. The examples of new business areas include composite materials, biochemicals, bio-based fuels etc. Thus, the Swedish pulp and paper industry as a whole serves as the second main case study in the thesis, and distinct innovation initiatives (that result in new products or processes) are the sub-cases within this main case.

The choice of a qualitative methodology was motivated by the need to obtain a holistic picture and an in-depth understanding of the studied phenomena (Rynes and Gephart Jr 2004). The central phenomena studied in the thesis are endogenous innovation and its underlying mechanisms. As the theoretical overview has shown, current research lacks detailed understanding as well as a generally accepted conceptualization of these phenomena. Therefore, an overall, inductive investigation is required with the help of qualitative tools that can lead to theory building and extension-i.e. a case study (Eisenhardt 1989).

It needs to be noted that although the case study involves two main industries, the research design is not fully comparative. Initially there was no intention to directly compare and contrast the two industries along some set of criteria. Instead, the findings from both industries were meant to complement each other, and the study of the second industry was built on the findings of the first. Therefore, no comparison between the two main cases takes place in the five appended papers. However, the thesis cover paper (kappa) provides an integrated analysis in which the findings from the two case studies are synthesized and compared.

The embedded design of both case studies suggested that within each industry case there were subcases that were analysed in more detail. The existence of sub-cases was partially a consequence of the nature of the studied phenomena since innovation in mature industries implies the co-existence of both established (or old) technologies and products as well as new ones. Unlike the two main 
cases, the subcases had already been analysed comparatively in the appended papers. For example, new technologies in the lighting industry were compared with respect to driving and enabling mechanisms, and new products in the pulp and paper industry were compared with respect to different aspects of newness. These comparisons served to established a replication logic across different sub-cases and increased the validity of the findings (Eisenhardt 1989).

Further, more specific methodological characteristics of each of the case studies were shaped under the influence of the features of the industries themselves. Thus, in the lighting industry the process of appearance of new technologies stretched over the whole $20^{\text {th }}$ century, which motivated the use of a historical, retrospective case study that allowed me to trace innovation and technology development patterns over long time periods. In contrast, the innovation processes in the pulp and paper industry were quite recent, suggesting an interview-based study. The use of interviews with manufacturers also fitted well with the ambition to understand the perspective of individual companies on the endogenously driven innovation process in the second case study.

The theoretical case sampling (Eisenhardt 1989) led to a combination of two quite different industries in the thesis. In the lighting industry, I studied the process of interaction and co-existence of multiple technologies, while in the pulp and paper industries the studied new products and processes were based on particular (although not always the same) pulping technologies and did not involve interactions or synergies across several technologies. Further, innovations in the lighting industry remained in the lighting market, while pulp and paper companies diversified into completely new business areas. On the one hand, this can be seen as an advantage of the study since it allowed me to take into account and study the implications of a variety of contexts, thereby increasing the external validity of the findings (Eisenhardt and Graebner 2007). On the other hand, it made it more challenging to directly compare the results from the two studies. However, since the ambition was to study partially different phenomena with each industry case, the differences between the industries' characteristics were not a major problem with respect to achieving the purpose of the thesis and answering the research questions.

As with any research methodology, qualitative methods have their limitations. One problem often discussed with regard to case studies is their generalizability. To what extent can the findings of these particular industries be applied to a variety of mature industries, especially given that considerable differences could be observed even between the two industries studied in the thesis? The purpose of this study was to better understand the phenomenon of endogenous innovation as well as to show that endogenous mechanisms can in fact lead to highly innovative outcomes. 
Therefore, a limited number of cases was enough to prove that the phenomenon exists (i.e. innovations can be enabled and sustained by industry endogenous mechanisms) and to capture the overall logic behind it (i.e. to understand how these mechanisms can be described and conceptualized). A more detailed discussion of generalizability of the findings can be found in Section 3.4.

\subsection{The case studies}

\subsubsection{The lighting industry study}

As discussed in the theoretical section of the thesis, mature industries are often considered to be path dependent, and path dependency is a central part of the currently dominant understanding of innovation dynamics in such industries. Moreover, the analysis of the current understanding of industry endogenous innovation mechanisms, which is at the core of this thesis, has led to the suggestion that the further conceptualization of those mechanisms be built with the help of analytical tools that belong to path dependency; namely, self-reinforcing mechanisms and reactive sequences. All of that made path dependency one of the main concepts used in the thesis. However, a formal description of the lighting industry did not fit the established view of path dependent industries at all as the lighting industry was both multi-technological and innovative, whereas path dependent industries are conceptualized as non-innovative and bound to a single technological solution.

Therefore, the lighting industry study focused on investigating whether this industry is indeed path dependent. The analysis was performed in two steps. In the first step, the analysis was concerned with understanding whether technological paths can be found in the multi-technology lighting industry, and in the second step, the analysis focused on whether the dynamic attributes of path dependency—such as self-reinforcing mechanisms and reactive sequences—can be applied to the lighting industry.

Thus, the starting point in the lighting industry study was the analysis and identification of technological paths. Since path dependency theory strongly associates technological paths with the notion of persistence, it was necessary to choose data sources that would reveal technological persistence. Previous studies suggested that patents are an appropriate way to study patterns of cumulative and persistent technological development (Fai 2003), which is why patents were chosen as the data source for this stage of the research. 
The patent study of the lighting industry was based on the database of the US Trademark and Patent Office (US PTO). The relevant patents of three leading lighting manufacturers (General Electric, Osram/Siemens, and Philips) for a period of 35 years (1976-2011) were retrieved and analysed. The scope was limited to these three companies as they have remained leaders in the industry for a long time, had a combined market share of over 60\% (Global Industry Analysts 2011), and have been leading patenting in both traditional lighting classes (Sanderson, Simons et al. 2008) as well as in LED-related areas (Woodside Capital Partners International 2012).

The relevant patents were found in several steps. First, all of Osram's patents (the one company that fully specializes in lighting) were analysed and the most frequently used patent classes were identified. Then, the resulting list of patent classes was completed based on the class descriptions of the International Patent Classification, previous studies of lighting (Sanderson, Simons et al. 2008), and the IPC-Standard Industrial Classification concordance table compiled by Silverman (2004). In addition, the list of patents was complemented with patents found via a keyword search (which was especially relevant for LED-related patents, which were not associated with any particular patent class).

As a result, 7,614 patents were retrieved and analysed. Among them 2,133 patents belonged to General Electric and its subsidiaries, 2,305 to Osram/Siemens and its subsidiaries, and 3,176 to Philips and its subsidiaries.

The analysis of patents was performed with the help of a number of indicators which were developed to capture technological persistence in a multi-technology industry. Three main groups of indicators were used. First, persistence within an overall lighting path was studied by measuring the patent shares and development trends of traditional lighting classes, the presence of traditional lighting classes in patents related to newer technologies, and the share of references to companies' own lighting patents. Second, persistence inside multiple technological paths was observed by measuring patent references within narrowly defined lighting technologies as well as the simultaneous use of two or more subclasses of the same main class in one patent. Third, interaction between paths was indicated by the simultaneous presence of different technology-specific classes in the same patents and the presence of traditional classes in patents related to the new technology. A detailed description of the patent analysis can be found in Paper 1.

The second step in the lighting industry study was an analysis of the logical forces behind the technological paths, i.e. self-reinforcing mechanisms and reactive sequences. In order to capture these dynamic relations, the data sources needed to be able to reveal repeated patterns of events 
and the causal relations between them. Interviews are often considered to be the primary source of such rich types of data. However, in the study of the lighting industry the relevance of interviews was decreased due to the retrospective character of the study. The causal relations between events needed to be considered over a period of several decades in order to take into account not only recent development patterns and their explanations, but also more distant events, including the process of formation and the early development of lighting technologies. Interviews could not provide this kind of data since many people involved in the early development of, e.g., fluorescent technologies were likely to be retired, and much important information about distant events might have been forgotten. Conversely, secondary data sources, such as archival documents, represented an appropriate data source for this part of the study since the history of technological development in the lighting industry in general as well as the development of particular technologies were well reflected in industry journals, studies, and reports. Therefore, secondary and archival data sources were mainly used in this part of the thesis.

Relevant data sources were gathered in several steps. First, annual reports of leading lighting manufacturers (General Electric, Osram/Siemens and GE) were considered for a period of 17-30 years, depending on availability. Second, market and technology reports as well as previous studies of lighting were analysed. Third, the contents of industry journals were reviewed: the Lighting Research and Technology Journal for the period 1969-2012, the Journal of Light and Visual Environment for the period 1977-2012, and the LEDs Magazine for the period 2005-2013. In addition, specialized information searches were undertaken with regard to different aspects of industry development that were highlighted as important, e.g. development of certain specific applications. Although interviews were not used as the main data source, they were still able to support the use of secondary data sources by confirming general findings or providing specific information. For example, technology development patterns focusing on the latest LED development were discussed in interviews with lighting manufacturers and an industry association, whereas application and market issues were discussed in interviews with retailers and a construction company. All the data sources gathered in the lighting industry study are summarized in Table 2 .

Table 2. Data sources used in the lighting industry study

\begin{tabular}{|l|l|}
\hline Data Source & Details \\
\hline Patents & USPTO database 1976-2011 \\
& 2,133 patents of GE and subsidiaries \\
& 2,305 patents of Osram/Siemens and subsidiaries \\
& 3,176 patents of Philips and subsidiaries \\
\hline
\end{tabular}




\begin{tabular}{|l|l|}
\hline Annual reports & $\begin{array}{l}\text { GE, 1987-2014 } \\
\text { Osram/Siemens, 1985-2014 } \\
\text { Philips, 1998-2014 }\end{array}$ \\
\hline Industry Journals & $\begin{array}{l}\text { Lighting Research and Technology Journal, 1969-2012 } \\
\text { Journal of Light and Visual Environment, 1977-2012 } \\
\text { LEDs Magazine, 2005-2013 }\end{array}$ \\
\hline Industry, market and technology reports & $\begin{array}{l}\text { e.g., IEA (2006), OECD/IEA (2010), McKinsey \& Company (2011), ALG } \\
\text { (2012) }\end{array}$ \\
\hline Interviews & $\begin{array}{l}\text { e.g., Menanteau and Lefebvre (2000), Sanderson et al. (2008), Sanderson } \\
\text { and Simons (2014) }\end{array}$ \\
$\begin{array}{l}3 \text { interviews with manufacturers (Osram Senior Vice President, Philips } \\
\text { Vice President Light Sources and Electronics, Philips Vice President } \\
\text { Sustainability, Standards and Regulation), } \\
2 \text { interviews with wholesalers (IKEA technician, ICA Product Manager for } \\
\text { lamps), } \\
1 \text { interview with a construction company (Lambertsson depot manager for } \\
\text { electricity), } \\
1 \text { interview with an industry association (LED Working Group Chair at } \\
\text { Global Lighting Association). }\end{array}$ \\
\hline
\end{tabular}

The analysis of secondary data was performed by means of tags and empirical questions associated with technology development patterns and their underlying causal mechanisms, i.e. self-reinforcing mechanisms and reactive sequences. Self-reinforcing mechanisms were tagged along the mechanism type (one of four types described in the path dependency theory), locus (related to technology adoption or development), direction of influence (whether influence occurred within one technology or across technologies), and character of influence (positive or negative). Considering the overall thesis purpose, it was the explicit attention to the direction of influence and the character of influence when combined together that revealed the self-reinforcing mechanisms that can be characterized as industry endogenous innovation mechanisms. Further, a detailed analysis of three particular technologies (incandescent, fluorescent lighting, and LED) was performed with the focus on the driving forces behind the development of the existing incandescent path, on the one hand, and the enabling of new fluorescent and LED paths, on the other. The sets of driving forces were compared and interpreted from the perspective of reactive sequences. The existence of the same driving forces behind both existing and new technologies pointed to the endogenous character of mechanisms behind new technology generation in the lighting industry. A detailed description of secondary data analysis process can be found in Papers 2 and 3. 


\subsubsection{The pulp and paper industry study}

As mentioned above, the main ambition with the pulp and paper industry study was to investigate the companies' perspective with regard to the industry endogenous innovation mechanisms by taking a closer look at company strategies. This kind of theoretical problem suggests the use of company-specific data. In addition to that, the data needed to be rich, i.e. able to indicate causal relations, as well as the logic behind different events and decisions. Moreover, the innovation processes to be studied in the pulp and paper industry were rather recent (and some are still ongoing), which is why interviews with company representatives were considered as an appropriate main source of data.

Twenty one semi-structured interviews were conducted with seven manufacturers and three research institutes in the Swedish pulp and paper industry. The companies to be approached were chosen depending on their general interest in pursuing innovation activities outside their traditional areas of business (this could be judged from companies' homepages as well as their strategic statements). The interviewees from the companies were chosen depending on their direct involvement in innovation initiatives outside traditional business areas, e.g. heads or representatives of divisions specializing in such initiatives (specialized divisions have been recently established in a number of companies). Furthermore, since many innovation projects involved research institutes, some of the interviews were conducted with representatives of research institutes who have been participating in or coordinating these initiatives.

One part of the interviews was of an overall character, where general company strategies with respect to new business development opportunities and challenges as well as the role of existing resources in these processes were discussed. The other part of the interviews focused on particular innovation initiatives and inquired in detail about their initiation, development, and any implications for the involved companies. To prevent steering the answers of the interviewees, in both types of the interviews the questions encouraged the respondents to describe freely the companies' approaches to new business development or the course of development of particular initiatives. In addition to 21 main interviews, several follow-up interviews were conducted in order to clarify some specific issues that arose during data analysis.

To support and triangulate the data gathered with the help of the interviews, additional information on company strategies as well as specific innovation initiatives were gathered by studying companies' annual reports, press releases, media articles, technology- and initiative-dedicated websites. All data sources gathered in the pulp and paper industry study are summarized in Table 3 . 


\begin{tabular}{|c|c|}
\hline Data Source & Details \\
\hline Interviews & $\begin{array}{l}16 \text { main interviews and } 2 \text { follow-up interviews with } 7 \text { leading pulp and paper } \\
\text { manufacturers: } \\
\text { - } \quad \text { Company A: Manager strategic planning and research, Business development } \\
\text { - } \quad \text { manager, Project manager, Senior advisor; } \\
\text { - Company B: Production manager, Technical manager, R\&D manager; } \\
\text { - Company D: Technical manager, R\&D coordinator; } \\
\text { - Company E: Senior Vice-President, Project managers; } \\
\text { - Company F: Vice-President; } \\
\text { - Company G: President of R\&D Centre. } \\
\text { - } \quad \text { interviews with } 3 \text { pulp and paper research institutes: } \\
\text { - } \quad \text { Research Institute 1: President; } \\
\text { - Research Institute 2: Vice-President, Principal scientist, Focus Area Manager; } \\
\text { 1 follow-up interview with a downstream actor involved in one of the innovation } \\
\text { initiatives (company founder). }\end{array}$ \\
\hline Annual reports & 6 leading pulp and paper manufacturers, 2010-2014 \\
\hline Other & $\begin{array}{l}\text { Homepages of manufacturers, dedicated project websites, media articles, press releases, } \\
\text { industry reports (e.g., Backlund and Nordström 2014) }\end{array}$ \\
\hline
\end{tabular}

Analysis of the interviews and additional data sources was performed, first, by categorizing specific examples of innovation initiatives and evaluating the driving forces behind them, and second, by identifying the various types of existing resources and evaluating their influence on the innovation process and outcomes. Thus, 11 innovation initiatives with sufficient amount of available information that showed product and/or process newness were selected for a deeper analysis. Those initiatives were categorized with regard to the degree of newness in terms of process and products as well as primary and final steps in the value chain. The main driving forces of the initiatives were identified, i.e. whether the initiatives were driven by the ambition to exploit existing products, processes or steps in the value chain, or whether they were driven by the ambition to develop something new. This part of the analysis contributed to revealing whether the exploitation innovation strategy had an enabling role in the innovation process. Further, interview transcripts and other data sources were tagged with respect to different resource types, contexts in which they were discussed (new or existing, general vs project-specific), and their influence on the innovation process (enabling vs hindering). Based on this tagging, the main patterns of influence of different 
resource types on innovation were revealed and interconnections between the roles of different resources were identified. A more detailed description of the analysis of interviews and other data sources in the pulp and paper industry can be found in Papers 4 and 5.

A summary of case studies with respective data sources and analysis methods can be found in Table 4.

Table 4. Summary of data sources and analysis methods

\begin{tabular}{|c|c|c|c|}
\hline Case study & Main data source & Data analysis method & $\begin{array}{l}\text { Reported in } \\
\text { Appended paper }\end{array}$ \\
\hline \multirow[t]{3}{*}{$\begin{array}{l}\text { Lighting } \\
\text { industry }\end{array}$} & Patents & $\begin{array}{l}\text { Patents analysis along a list of theoretically derived } \\
\text { indicators }\end{array}$ & $\begin{array}{l}\text { Paper } 1 \text { (and } \\
\text { Paper 2) }\end{array}$ \\
\hline & \multirow[t]{2}{*}{ Secondary data } & $\begin{array}{l}\text { Qualitative identification and categorization of self- } \\
\text { reinforcing mechanisms along theoretically derived } \\
\text { tags }\end{array}$ & Paper 2 \\
\hline & & $\begin{array}{l}\text { Qualitative analysis of three technology cases guided } \\
\text { by theoretically derived questions }\end{array}$ & Paper 3 \\
\hline \multirow[t]{2}{*}{$\begin{array}{l}\text { Pulp and } \\
\text { paper industry }\end{array}$} & \multirow[t]{2}{*}{$\begin{array}{l}\text { Interviews \& } \\
\text { secondary data }\end{array}$} & $\begin{array}{l}\text { Categorization of innovation initiatives using the } \\
\text { theoretically derived analytical framework and } \\
\text { qualitative analysis of logical connections between } \\
\text { different dimensions of the framework }\end{array}$ & Paper 4 \\
\hline & & $\begin{array}{l}\text { Categorization of the influence of different resource } \\
\text { types along theoretically derived tags and qualitative } \\
\text { analysis of logical connections between different types } \\
\text { of resources and their respective influences }\end{array}$ & Paper 5 \\
\hline
\end{tabular}

\subsubsection{Joint analysis of the cases in the kappa}

Each of the five appended papers deals with a specific, separate part of the overall purpose of the thesis, partly as a consequence of the paper-specific purpose and research questions and partly (and interrelatedly) as a consequence of the data sources chosen and method of analysis. Altogether, the papers build the argument of the thesis and provide the pieces of the puzzle that fit together to answer the thesis questions.

However, the process of kappa writing also involved a joint analysis of the results of all the papers, which allowed synergies to be found where insights from one industry study (or one appended paper) enriched and provided a new perspective on the results of another study (or another appended paper). As mentioned above, while each appended paper resulted from one of the two 
industry studies, the kappa also contains a comparative analysis of both industry studies. Below I summarize the kind of analysis that took place in the process of developing answers to the thesis research questions.

Answering the first research question of the thesis was based primarily on the findings from Papers 2 and 3, as they directly focus on self-reinforcing mechanisms and reactive sequences that can be further conceptualized as industry endogenous innovation mechanisms. In addition, the findings from Papers 4 and 5 were reconsidered from the perspective of industry-level patterns, which allowed several industry endogenous innovation mechanisms in the pulp and paper industry to also be identified. This provided a foundation for a comparison between the two industries, which served to increase the external validity of the results and bring nuance to the understanding of the various innovation contexts found in mature industries.

Answering the second research question was mainly based on findings from Papers 4 and 5 as these papers consider the role of the exploitation strategy in general and different resource types in particular during the innovation process. However, the results of these papers were additionally reinterpreted to explicitly highlight the role of resources that were not under the direct control of companies. In order to do this, the interview transcripts were revisited with the focus on general technology and product attributes, as well as the resources of others. In addition, the results of the lighting industry study were reconsidered from the perspective of agency, which allowed for a new interpretation of the company-level persistence patterns discussed in Paper 1 and the technology development-related self-reinforcing mechanisms discussed in Paper 2.

Answering the third research question required the integration of results from all the appended papers in order to reveal the influence of the endogenous character of underlying innovation mechanisms on the resulting range of radical innovations. To accomplish this, theoretically derived aspects of radicalness were applied to the whole range of innovation examples considered throughout the papers. In some cases, this analysis at least partially overlapped with the analysis already performed in the papers (e.g. assessing the newness of product vs process dimensions in Paper 4), but in many other cases the assessment of newness along different aspects, although indirectly implied in the papers discussions, was not explicitly formulated and therefore needed to be performed in the kappa analysis. In order to achieve this, the data sources were reconsidered from new perspectives. For example, the differences between lighting technologies were considered from the perspective of implications for production processes, plants, and other resources. Further, pulp and paper industry interviews were revisited considering how the performance criteria of new 
products were discussed. It also needs to be noted that the discussion of interconnections between different aspects of radicalness, which was part of the answer to the third research question, involved further comparison between the two industries and the kinds of innovations enabled in the two different contexts.

\subsection{Reflection on some methodological challenges}

As follows from the study purpose and the overall research design, industry is the primary unit of analysis in the thesis, and it is industry-level phenomena (industry endogenous innovation and industry endogenous innovation mechanisms) that are of the main interest of the thesis. In addition, the second research question is concerned with company-level processes, making the company another (supplementary) unit of analysis. Analysis of both industries and companies is based on observations of particular technologies (in the lighting industry) and projects (in the pulp and paper industry). These are not considered as separate units of analysis, but are rather methodological instruments for approaching the industry and the company levels.

Combining the two units and, hence, levels, of analysis in the thesis constituted one of the major methodological challenges of the study. While it is a challenge in itself to design a study in a way that the results would be relevant for all (or most) actors in the industry considered, it is especially demanding to use both levels as doing so requires an awareness of where to draw the line between company-level and industry-level findings.

In this thesis, the lighting industry study primarily addresses the industry-level processes. To ensure that the results are relevant for the industry as a whole, several measures were taken. In the patent study, the industry level analysis considers integrated sets of patents (ones that involve all three leading companies in the industry), and provides comparisons between individual companies where similarities across all studied companies can be considered as a sign of industry-level phenomena. When using secondary data, one way to ensure the relevance of findings for the whole industry, rather than just for individual companies, is to combine a variety of sources that together provide sufficient evidence of the widespread character of the phenomena studied. In addition, the focus on technologies rather than companies (as in the lighting industry study) allows abstracting from the positions and strategies of individual companies in order to consider a broader technology field.

When it comes to combining the two levels of analysis, the challenge arises from the difficulty of, on the one hand, making company-level conclusions based on industry-level patterns, and, on the other hand, generalizing from the company to the industry level. In the thesis this challenge is handled 
with the help of data source triangulation. For example, when considering the roles of individual companies in shaping industry-level mechanisms, the industry-level analysis is complemented with the analysis of annual reports and interviews with companies, which can reveal the applicability of specific industry-level mechanisms to the strategy of a particular company. Further, when generalizing about the whole industry based on company-level data, this thesis builds on, first, comparing patterns across a large number of industry participants, and second, gathering expert opinions from, e.g. research institutes that drive basic research in the field and have a long history of collaboration with most companies in the industry.

With regard to the purpose of the thesis, the choice of methodology has served to ensure high levels of both reliability and validity. High reliability was achieved by combining and triangulating a variety of data sources throughout the study. As the above discussion of the choice of data sources shows, in most of the papers the main data source was chosen and supported by the use of additional data. A partial exception here is Paper 1, the results of which have nevertheless been further confirmed in Papers 2 and 3. Ensuring internal validity is challenging because one of the ambitions of the thesis is to provide a conceptualization for previously understudied phenomena. An important way of ensuring internal validity throughout the thesis was to provide clear definitions of the constructs used and to establish clarity and consistency with regard to how these constructs were operationalized (Rynes and Gephart Jr 2004). Therefore, the thesis applied the same criteria for analysing different examples of self-reinforcing mechanisms and reactive sequences in the lighting industry, as well as applying transparent and consistent criteria for assessing the innovativeness of innovation initiatives in the pulp and paper industry.

External validity is an acknowledged concern in case studies. The approach taken in this thesis opens several possibilities for generalizing the results. First, the findings of each industry study can be valuable in various contexts that depend on the specific characteristics of the studied industries. For example, the lighting industry is a multi-technology industry and was mainly studied from that perspective, which is why the patterns of inter-technology interactions studied should be especially interesting in other multi-technology contexts. That includes primarily other multi-technology industries (e.g., batteries, aircraft), but also multi-technology corporations (cf. Granstrand and Sjölander 1990). In both multi-technology industries and corporations, an understanding of the dynamics of non-competitive technology interactions leading to mutual benefits is an important prerequisite for long-term success. Further, the findings of the pulp and paper industry study can be especially relevant for process industries (in terms of the patterns of interaction that have been 
discovered between the product and process dimensions of innovation) as well as industries characterized by complex value chains (in terms of collaborations that cover the whole value chain). Second, as discussed above, in the analysis part of the kappa the lighting industry study was reinterpreted from the perspective of agency and the pulp and paper industry study was considered in terms of industry-level patterns. This not only provided the foundation for a comparison between the two industries, but also helped to improve the overall generalizability of the findings. The main argument of the thesis-i.e. that innovations of any level of magnitude can be endogenously enabled in mature industries - is formulated with respect to mature industries in general. The analysis performed in the kappa highlighted that this main argument is applicable for both process and assembly industries (e.g. LED is an assembly technology), consumer-oriented and B2B environments, as well as diversification and non-diversification innovation contexts. Although further research is needed to deepen the understanding of industry endogenous innovation mechanisms (see section 6.1), this thesis provides an initial range of different contexts where the logic of endogenous innovation is applicable. 


\section{Papers and findings}

This section presents the appended research papers as well as describes my contribution to each of the papers. Table 5 provides a summary of the papers' titles and their current publication status.

Table 5. The Appended Papers

\begin{tabular}{|l|l|l|l|l|}
\hline $\begin{array}{l}\text { Paper } \\
\text { ID }\end{array}$ & Paper title & Authors & Publication status & $\begin{array}{l}\text { Primary } \\
\text { RQ }\end{array}$ \\
\hline Paper 1 & $\begin{array}{l}\text { Is one path enough? Multiple paths and path } \\
\text { interaction as an extension of path dependency } \\
\text { theory }\end{array}$ & $\begin{array}{l}\text { Bergek, A.; } \\
\text { Onufrey, K. }\end{array}$ & $\begin{array}{l}\text { Industrial and Corporate } \\
\text { Change (2013), 23:5, } \\
1261-1297\end{array}$ & RQ 3 \\
\hline Paper 2 & $\begin{array}{l}\text { Self-reinforcing mechanisms in a multi-technology } \\
\text { industry: understanding sustained technological } \\
\text { variety in a context of path dependency }\end{array}$ & $\begin{array}{l}\text { Onufrey, K.; } \\
\text { Bergek, A. }\end{array}$ & $\begin{array}{l}\text { Industry and Innovation } \\
\text { (2015), 22:6, 523-551 }\end{array}$ & RQ 1 \\
\hline Paper 3 & $\begin{array}{l}\text { Endogenous sources of path generation in a path } \\
\text { dependent industry }\end{array}$ & Onufrey, K. & $\begin{array}{l}\text { Technology Analysis \& } \\
\text { Strategic Management } \\
\text { (2016): 1-14 (published } \\
\text { online) }\end{array}$ & RQ 1 \\
\hline Paper 4 & $\begin{array}{l}\text { Second wind for exploitation: pursuing high } \\
\text { degrees of product and process innovativeness in } \\
\text { mature industries }\end{array}$ & $\begin{array}{l}\text { Onufrey, K; } \\
\text { Bergek, A. } \\
\text { industry }\end{array}$ & $\begin{array}{l}\text { Under review in the } \\
\text { Technovation Journal }\end{array}$ & RQ 2 \\
\hline Paper 5 & $\begin{array}{l}\text { The role of existing resources in developing } \\
\text { exploitation-driven innovations in a mature }\end{array}$ & $\begin{array}{l}\text { Onufrey, K. } \\
\text { Industry and Innovation } \\
\text { Journal }\end{array}$ & RQ 2 \\
\hline
\end{tabular}

\subsection{Paper 1}

\subsubsection{Summary}

Paper 1 addresses the notion of technological paths in the context of multi-technology industries by providing a conceptualization of multiple paths and path interactions. Building on the current association of the path concept with technological persistence, Paper 1 develops an analytical framework that includes not only unitary (typically leading to lock-in), but also multiple (parallel, convergent or divergent) progression patterns.

The suggested framework is validated in a patent study of three leading manufacturers in the lighting industry, General Electric, Osram/Siemens, and Philips. The results show that each of the three companies, as well as the industry as a whole, are technologically persistent. Analysis of patents reveals that companies, first, persistently use a specific range of patent classes over a period 
of 35 years across all technologies, including the recently added LED technology; and second, have limited references to their own patents outside the lighting field. Further, strong similarities between companies' patterns indicate that technological persistence is also characteristic for the lighting industry as a whole.

Paper 1 contributes to the previous literature by showing that co-existing technologies can be conceptualized as parallel technological paths that, on the one hand, develop separately from each other, and on the other hand, interact in a positive way through patent co-classification across paths. Cross-path interactions provide evidence that even radically new technologies (such as LED) can be at least partially rooted in previously existing paths. This is the first indication of the high potential of established companies in mature industries to endogenously develop radically new technologies.

\subsubsection{My contribution and publication status}

This paper was co-authored with Anna Bergek, who is the first author. Anna took the lead in developing the conceptual design and the theoretical framing of the paper, and I performed the data collection (design and implementation of patent search strategy) and together with Anna actively participated in the data analysis. Both Anna and I contributed to discussing, writing, and revising all parts of the paper. Early versions of the paper were presented at the KITE Workshop in May 2012 in Linköping, at the 14th ISS Conference in Brisbane, and at the "Knowledge Dynamics, Industry Evolution, Economic Development" summer school in Nice in July 2012. Using the feedback from those discussions, the paper was revised and submitted to the Industrial and Corporate Change journal where it was published after several rounds of revision.

\subsection{Paper 2}

\subsubsection{Summary}

Paper 2 takes its departure from the existing literature on self-reinforcing mechanisms and addresses the gaps that exist in relation to understanding self-reinforcing mechanisms in multitechnology industries. Multi-technology industries represent a specific context for studying path dependent processes driven by self-reinforcing mechanisms since the co-existence of several technology paths implies the existence of cross-path interactions. More specifically, Paper 2 explores what kind of self-reinforcing mechanisms can be present in industries where no lock-in to a single technology has taken place, and what the role of self-reinforcing mechanisms in enabling the survival of several technologies is. 
Building on the empirical example of the multi-technology lighting industry, the results show that all four commonly accepted types of self-reinforcing mechanisms can exist in multi-technology industries, i.e. evidence of coordination effects, complementarity effects, expectation effects, and investment and learning effects were found across different technology lighting paths. However, in contrast to the established understanding of self-reinforcing mechanisms that includes positive feedback loops within technologies and negative cross-technology externalities, Paper 2 also finds that cross-technology interactions can take the form of positive externalities that reinforce all the paths involved. Having explicitly distinguished between technology adoption and technology development mechanisms, Paper 2 shows that positive cross-technology externalities in the lighting industry are mainly of technology development character.

Most importantly, the existence of positive externalities proves that instead of outcompeting each other, co-existing technology paths can mutually reinforce one other. In that process, synergies and spillovers between co-existing technologies occur that enable technological advances in one technology to contribute to corresponding technological advances in other technologies. In contrast to most of the path dependency literature, these findings imply that some industries can be innovative not in spite of path dependency and self-reinforcing mechanisms, but due to them.

\subsubsection{My contribution and publication status}

This paper was co-authored with Anna Bergek and I am the first author. I suggested the initial idea of the paper and wrote the first version of the theoretical framing. Both Anna and I contributed to data gathering and the initial analysis: Anna focused on gathering and screening industry and technology reports as well as previous studies of lighting, and I focused on screening the contents of industry journals and conducted the interviews. An early version of the paper was presented at the R\&D Management Conference in Manchester in June 2013. After that, the paper was reframed as a result of discussion between and contributions from both co-authors. I took the lead in the continued process of data analysis, which involved the active participation of both Anna and myself in coding the data and analysing the results. We both contributed to writing and revising the text of the paper. A revised version of the paper was submitted to the Industry and Innovation journal where it was published after several revisions.

\subsection{Paper 3}

\subsubsection{Summary}

Paper 3 takes a closer look at the process of path generation in a path dependent industry. Following the evolutionary theory of economic change, which highlights the crucial role of 
endogenously driven innovations resulting from the interplay between the processes of selection and variety creation, Paper 3 investigates industry endogenous sources of innovation in the context of path dependency, where the phenomenon of endogenous innovation has so far been largely neglected. In particular, the paper explores how the dynamics of an existing technology path can enable the generation of a new path in a mature industry.

The paper is based on an embedded case study of the mature lighting industry, where two cases of path generation were considered in more detail - fluorescent lighting and LEDs. The results show that in both cases, technology generation was enabled by the same driving forces that were pushing the development of the established incandescent technology. In particular, a variety of lighting applications together with widely different and difficult to combine performance criteria created an environment where the existing technology was continuously exposed to possibilities and had incentives to develop further. There also existed the potential and need for other technologies to appear.

Common driving forces behind the development of the established technology and the enabling of the new ones points to the existence of a reactive sequence or a causal relationship from existing to new technology. This also proves the endogenous nature of technological path generation in these cases. Therefore, Paper 3 contributes to the previous research by showing that endogenous innovation can take place in the context of technological path dependency, which-from the broader perspective of evolutionary economics-also implies that mature industries can and do develop internal preconditions for continued variety creation.

\subsubsection{My contribution and publication status}

I am the single author of the paper; I planned, designed, and wrote all parts. However, it should be noted that the paper is partially based on the same data as Paper 2, which means that I used and further analysed secondary data sources previously collected by both myself and Anna Bergek. An early version of the paper was presented at the DRUID Society Conference in Copenhagen in June 2014. Using the feedback from the conference as well as comments and feedback from Anna throughout the paper writing process, I revised the paper and submitted it to the Technology Analysis and Strategic Management journal, where it was accepted for publication after several revisions. 


\subsection{Paper 4}

\subsubsection{Summary}

Paper 4 investigates how the exploitation innovation strategy can enable innovations characterized by a high degree of newness. Based on the current research on the exploitation innovation strategy, in which the generally accepted association of this strategy with incremental innovative outcomes has been recently challenged, Paper 4 answers the current call for a more open approach to the kinds of innovation that are possible under an exploitation-oriented innovation logic. In particular, Paper 4 considers 11 innovation initiatives in the Swedish pulp and paper industry, on the one hand, from the perspective of product-process interactions, and on the other hand, considering multiple stages in the value chain. Based on that, the paper develops and applies an analytical framework that considers different innovation dimensions: primary process, primary product, final process, and final product newness.

The results show that the initiatives analysed had high levels of newness with respect to one or several innovation dimensions. At the same time, all but one initiative had some dimensions that were unchanged or modified (not completely new), i.e. were exploited in the innovation process. The analysis also reveals the existence of enabling logic from exploited dimensions to the development of new ones. For example, exploitation of an existing process can justify changes in products, while exploitation of existing products can lead to the development of new processes. Similarly, the exploitation of resources in the primary step of the value chain can enable a high level of newness at the final stage and vice versa.

In sum, a simultaneous consideration of several innovation dimensions reveals a range of innovation opportunities with the option to combine exploited and new aspects. This approach therefore provides evidence that the exploitation innovation strategy can enable innovations characterized by a high a degree of newness. From a more general perspective, these results also challenge the view on established companies in mature industries as non-innovative.

\subsubsection{My contribution and publication status}

The paper was co-authored with Anna Bergek, with myself as first author. I suggested the initial idea, which I further developed into a poster that was presented at the International Sustainability Transitions Conference in Brighton in August 2015. Further development of the paper was undertaken in collaboration with Anna. After discussing the conceptual design, Anna took the lead in writing the theoretical framework of the paper, and I gathered the data and took the lead in writing the analysis. Further, all parts of the paper were discussed by and received input from both 
co-authors. The paper was presented at the DRUID Society Conference in Copenhagen in June 2016. Using the feedback from the conference as well as the previously received comments from Thomas Magnusson, the paper was further revised and submitted to the Technovation journal where it is currently under review.

\subsection{Paper 5}

\subsubsection{Summary}

Paper 5 takes a closer look at the influence of different resource types on the exploitation-driven innovation process in mature industries. The overview of the existing literature showed that the overall influence of existing resources as well as the particular roles of specific resource types are considered in different studies and research streams as either negative (hindering) or positive (enabling), which creates a contradictory overall understanding. To overcome this contradiction, Paper 5 considers the simultaneous positive and negative influences of different resource types as well as the interplay between those influences in the exploitation-driven innovation process. In particular, the roles of raw materials, plants, technological competences, market competences, company culture and risk attitude, value chain position, and network relations are investigated.

The analysis of innovation initiatives in the Swedish pulp and paper industry shows that existing resources can have three different types of influence on innovation. Apart from the enabling and hindering influences highlighted in previous research, the results of the paper also show that some resources have a limiting influence, i.e. direct innovation activities towards some alternatives and away from others.

Paper 5 also shows that two mechanisms of interplay between different types of influences are important for the innovation process. One mechanism is the activation-mode interplay, whereby some resource types, although they have a direct limiting influence on the innovation process, can at the same time reinforce the positive influence of other resource types. For example, the exploitation of existing raw materials and plants placed some limitations on the range of available innovation opportunities, but it also enabled a full exploitation of strengths with regard to technological competences. The other mechanism is the mitigation-mode interplay, whereby resources that have an enabling influence also help to decrease the hindering influence of other resources. For example, network relations not only had a direct enabling influence on the innovation process, but also helped to mitigate the hinders imposed by company culture and risk attitude. 
The findings of the paper also suggest that resource compatibilities between existing and new products can be strategically planned by companies because decisions to build on certain resource types lead to exploitation of those resources and resource types related to them.

All in all, the co-existence of different types of influences from existing resources as well as the outcomes of the two mechanisms of interplay between different influences explain how exploitation-driven innovation process can lead to highly innovative outcomes, even when some types of existing resources have a hindering or limiting influence on the innovation process.

\subsubsection{My contribution and publication status}

I am the single author of the paper which I presented at the 17th International Continuous Innovation Network Conference in Turin in September 2016. Using the feedback from the Conference and comments from Anna Bergek and Thomas Magnusson on several versions of the paper, I further revised it and submitted it to the Industry and Innovation journal. 


\section{Analysis}

In this section, the research questions of the thesis are answered based on the findings of the appended papers. Findings from different papers are considered together and synthesized in order to provide complete answers.

\subsection{Reactive sequences and self-reinforcing mechanisms as industry endogenous innovation mechanisms}

The first research question of the thesis focuses on industry endogenous mechanisms that can enable and sustain innovation in mature industries. The results of the thesis show that industry endogenous mechanisms can indeed enable and sustain innovation in mature path dependent industries. In particular, reactive sequences and self-reinforcing mechanisms were found to play the role of such innovation mechanisms.

Paper 3 shows that in the lighting industry the development of the established incandescent technology and the enabling of the new fluorescent and LED technologies were both driven by the same forces. In particular, a large variety of lighting applications together with widely different performance criteria, which were difficult to combine, created a development logic in which each technology could be used (and improved through that use) in a large number of applications, while at the same time there existed space for more than one technology. In the case of incandescent lamps, this development logic was due to constant improvement along criteria that were critical for that technology (e.g. energy efficiency), which led to such lamps being used in additional applications as well as further performance improvements. For fluorescent lamps and LEDs, the main enabling mechanism was the possibility of developing these technologies within certain applications (commercial lighting for fluorescent lamps and a chain of small niche applications for LEDs) until they improved enough to satisfy the requirements of more mainstream applications within domestic lighting.

The existence of the same development logic behind both the established technology and the enabling of new technologies showed that causal mechanisms that drove new technology generation were indeed industry endogenous. Further, since those causal mechanisms did not lead to pure pattern reproduction across technologies, but involved different applications and put emphasis on different performance criteria for all three technologies, this type of endogenous mechanism is characterized as a reactive sequence, which, according to the theory, is a causal 
mechanism where the outcome logically results from previous events, but does not necessarily reinforce them (Mahoney 2000, Araujo and Harrison 2002).

The above paragraphs discussed the process of new technology development enabled by endogenous innovation mechanisms. Apart from such innovation enabling, endogenous mechanisms are also able to contribute to sustaining technological variety, e.g. by supporting positive non-competing technology interactions or providing simultaneous benefits and development incentives for several co-existing technologies. Thus, in terms of sustaining already enabled innovations, the results of the thesis suggest that mechanisms for that are represented by self-reinforcing mechanisms. Paper 2 found that apart from positive feedbacks within one technology and the negative cross-technology externalities that were described in previous literature (Vergne and Durand 2010), self-reinforcing mechanisms can also take the form of positive cross-technology externalities. Evidence of such cross-technology externalities was found across all four types of self-reinforcing mechanisms and examples of such self-reinforcing mechanisms included the adaptation of new technologies to imitate certain features of incandescent lamps (coordination effect), the adaptation of new technologies to fit into existing fixtures (complementarity effect), sustained efforts throughout all technologies to improve energy efficiency of light sources (expectation effect), and cross-technology learning loops (investment and learning effects).

The finding that certain self-reinforcing mechanisms can enable the survival of several co-existing technologies, and thereby sustain technological variety in a mature industry, implies that selfreinforcing mechanisms can take on the role of industry endogenous innovation mechanisms. In contrast to reactive sequences, where the same causal mechanisms launched several different chains of technological development, these innovation mechanisms involved pattern reproduction across technologies, which was beneficial both for the technologies in which the pattern originated and those where the pattern was reproduced.

In summary, Papers 2 and 3 provide evidence that reactive sequences and self-reinforcing mechanisms can be considered to be endogenous innovation mechanisms that enable and sustain innovation in mature industries. However, it is important to note that both reactive sequences and self-reinforcing mechanisms were found to enable and sustain innovation in a particular setting, namely across co-existing multiple technologies. Although many mature industries are indeed multi-technology industries, innovation in mature industries does not obligatorily involve crosstechnology interactions, which is why a clear association of industry endogenous innovation 
mechanisms with the specific dynamics of a multi-technology industry could be perceived as a limitation of these findings.

This limitation can, however, be overcome if the findings of Papers 2 and 3 are considered in combination with the findings of Papers 4 and 5 that do not have the industry-level mechanisms in focus, but still offer a number of interesting observations if considered from the perspective of industry endogenous mechanisms. Papers 4 and 5 focus on innovation processes in the Swedish pulp and paper industry that are based on particular (although different) pulping technologies and do not involve cross-technology interactions. This means that cross-technology synergies or other dynamics were not influential for the innovations studied in the pulp and paper industry where examples of outcomes included new materials, products or production processes rather than new core technologies.

For example, Paper 4 shows that several innovation initiatives were driven by the intention to exploit an existing production process. In different cases process exploitation resulted in different innovation outcomes, which included lignosulfonates, single-cell protein, and composite material. But all these cases followed the same development pattern in which an existing production process was retained and only slightly modified to allow for the development of additional by-products (in parallel with the remaining main product), so that in the end both old and new products could be integrated in the same process. It needs to be noted that these cases not only shared the same development pattern, but were also driven by the same development logic in which the intention to take full advantage of the existing production process enabled the development of new products while also reinforcing the continued survival of existing products. Indeed, the importance of existing main products (i.e. paper pulp and dissolving cellulose) could only increase when an associated production process was proven to be flexible enough to incorporate additional, novel by-products. In path dependency terminology, such development logic can be characterized as a complementarity effect, i.e. a self-reinforcing mechanism in which a certain complementary resource (production process) enables the development of new products, but also reinforces the continued survival of existing products, which remain core to the innovating company. The existence of clear positive interconnections between old and new products also allows this selfreinforcing mechanism to be characterized as a positive externality and, consequently, as an endogenous innovation mechanism for the pulp and paper industry. It can also be noted that while the lighting industry study provided evidence of reactive sequences to enable innovations and selfreinforcing mechanisms to sustain them, this example shows that self-reinforcing mechanisms can also enable new product development in a mature industry. 
Another example can be found in Paper 5 which shows evidence of cross-product learning effects in the pulp and paper industry. Core competences of the pulp and paper industry include understanding the fundamental characteristics of wood fibres, separation technologies, and biomass chemistry. These areas of knowledge have traditionally served as a foundation for the development of the industry's main products, such as paper and packaging materials with various specific characteristics depending on the particular applications. However, Paper 5 shows that the same knowledge areas are actively exploited in the development of products and materials that are completely new to the industry, such as carbon fibre and other lignin-based and composite materials. Moreover, it is the exploitation of the competences accumulated over time that enables the development of these new products. This implies that exploitation of core technology competences can be seen as a common driving force behind the development of both existing and new products. It can be noted that in the case of each particular product, knowledge development takes different directions depending on the type of product or application, i.e. no exact pattern reproduction takes place. For example, in the Composite Material initiative, the understanding of how wood fibres interact with artificial fibres was crucial, while in the Carbon Fibre initiative the fundamental characteristics of lignin were most important. Nevertheless, both initiatives were driven by the exploitation of the core technological competences of the pulp and paper industry, which had been built in the process of developing products traditional to the industry. The evidence of such common driving forces points to the existence of a reactive sequence that both drives the development of existing products and enables new ones. Thus, as in the lighting industry study, in this example a reactive sequence serves as an industry endogenous innovation enabling mechanism. Examples of industry endogenous innovation mechanisms found in the thesis are summarized in Table 6.

Table 6. Examples of industry endogenous innovation mechanisms in the lighting and pulp and paper industries

\begin{tabular}{|c|c|c|}
\hline $\begin{array}{c}\text { Type of } \\
\text { mechanism }\end{array}$ & Character of influence & Examples \\
\hline \multirow{2}{*}{$\begin{array}{l}\text { Reactive } \\
\text { sequences }\end{array}$} & \multirow{2}{*}{$\begin{array}{l}\text { Enabling the } \\
\text { development of a new } \\
\text { technology or a } \\
\text { product }\end{array}$} & $\begin{array}{l}\text { Technology development driven by a variety of applications and } \\
\text { performance criteria (lighting industry) }\end{array}$ \\
\hline & & $\begin{array}{l}\text { Technology development driven by the exploitation of core technological } \\
\text { competences (pulp and paper industry) }\end{array}$ \\
\hline $\begin{array}{l}\text { Self- } \\
\text { reinforcing } \\
\text { mechanisms }\end{array}$ & $\begin{array}{l}\text { Enabling the } \\
\text { development of a new } \\
\text { technology or a } \\
\text { product }\end{array}$ & $\begin{array}{l}\text { Complementarity effect: development of novel by-products based on the } \\
\text { established production process while keeping the established main product } \\
\text { (pulp and paper industry) }\end{array}$ \\
\hline
\end{tabular}




\begin{tabular}{|l|l|l|}
\hline \multirow{2}{*}{$\begin{array}{l}\text { Sustaining the survival } \\
\text { of several co-existing } \\
\text { technologies or }\end{array}$} & $\begin{array}{l}\text { Coordination effect: adaptation of new technologies to imitate certain } \\
\text { features of the established one (lighting industry) }\end{array}$ \\
\cline { 3 - 3 } $\begin{array}{l}\text { products } \\
\end{array}$ & $\begin{array}{l}\text { Complementarity effect: adaptation of new technologies to adapt to existing } \\
\text { complementary assets (lighting industry) }\end{array}$ \\
\cline { 3 - 3 } & $\begin{array}{l}\text { Expectation effect: development of new technologies along performance } \\
\text { criteria relevant for the established technology (lighting industry) }\end{array}$ \\
\cline { 2 - 3 } & $\begin{array}{l}\text { Investment and learning effect: cross-technology learning loops (lighting } \\
\text { industry) }\end{array}$ \\
\hline
\end{tabular}

The above synthesized analysis shows that self-reinforcing mechanisms can take the form of industry endogenous innovation mechanisms not only in the case of interactions between multiple technologies, but also in a setting where new materials and products result from the development of a single core technology.

Furthermore, there is an interesting difference between the lighting and the pulp and paper industries. The lighting industry is a consumer industry in which the preferences and opinions of technology end users have a direct impact on manufacturers and the ways they present and position their products. On the contrary, the pulp and paper industry (especially to the extent studied in this thesis) belongs to the B2B segment, where end consumers do not directly interact with pulp producers. One implication of this difference between the two industries relates to the nature of typical self-reinforcing mechanisms in each industry. As Paper 2 shows, many technology-internal positive feedbacks and cross/technology negative externalities in the lighting industry belong to the technology adoption side, while considerably fewer such mechanisms have been found on the technology development side. For example, positive feedbacks around the incandescent technology were related to the consumers' sustained loyalty to the technology or their preferences for using existing fixtures that are compatible with incandescent lamps. However, positive cross-technology externalities (i.e. those mechanisms that actually drove innovation) were found mainly on the technology development side. This stark contrast between the two sides in terms of the balance between innovation-hindering and innovation-enabling mechanisms might create an image of an industry that is more locked-in in one aspect (technology adoption), than in the other (technology development). However, the findings from the pulp and paper industry study illustrate that both "traditional" self-reinforcing mechanisms that are considered to be hindering for innovation and innovation-enabling self-reinforcing mechanisms in the form of reactive sequences and crossproduct positive externalities can belong to the same aspect of industry development (e.g. technology development as in the case of the pulp and paper industry). Thus, "traditional" self- 
reinforcing mechanisms that are typical for the industry (e.g. investment and learning effect in the form of reluctance to switch to completely different types of business such as biofuels because it would jeopardize the use of existing facilities) belong to the technology development side. At the same time, both the examples of positive externalities and reactive sequences considered above (process complementarities and learning effects with regard to core technology competences) belong to the same aspect of industry development. This observation shows that innovation hindering and innovation enabling mechanisms can be rooted in the same industry characteristics. This also means that there are hardly any industry characteristics that can be unambiguously associated with either hindering or enabling mechanisms with regard to innovation.

The distinction between technology development and technology adoption mechanisms also provides an insight into the role of technology adoption processes in technology development. In several examples in the lighting industry case the inputs for innovation enabling mechanisms were rooted in consumer preferences. Thus, inherent variety of performance criteria and applications created preconditions for new technology development, and the stability of consumer preferences was used by manufacturers to adjust new technologies to make them more attractive for adopters. Importantly, consumer preferences per se were a part of innovation-hindering mechanisms, which is why turning those preferences into an innovation input required the active involvement of manufacturers. Therefore, the actual innovation enabling mechanisms were created at the technology development side. These findings complement the previous studies on the interaction between technology development and adoption (or technology supply and demand) by showing that pressures created by stable yet diverse customer preferences can be used by established companies to introduce more than incremental innovations (cf. Adner and Levinthal 2001, Tripsas 2008).

The findings in the appended papers allow one more important observation to be made with regard to the role of external influence in the innovation process in mature industries. In media discussion, LED lighting technology is often positioned as a disruptive change that comes from the semiconductor technology field and represents an external threat to established companies in the lighting industry. However, Paper 1 shows that to a considerable extent LED technology builds on the same range of patent classes as traditional technologies, and Paper 2 provides evidence that LED technology is at least partially driven by the same mechanisms that drive other technologies in the industry. All of that proves that even a radically new technology can be deeply rooted in the knowledge bases and mechanisms of a mature industry, and that external intervention disrupting the industry is not obligatory for such a technology to be developed. This finding is an important 
contribution to the existing literature on mature industries, where external shocks that disrupt the development logic of an industry or abandoning of existing resources are considered to be requirements for major innovation to happen.

In addition, the findings from Papers 4 and 5 provide a new perspective on the role of external influence in innovation in mature industries that is different from either the findings of the lighting study or the established perspective. The pulp and paper industry has for a long time been conservative in strategy and even criticized for being locked in (Novotny and Laestadius 2014). This has recently changed due to changes in the external environment: digitalization of many traditional markets (e.g. newspapers, magazines) has resulted in a decreased demand for printed paper; competition from Latin America has increased; and the societal calls for a transition to a bio-based economy have become increasingly explicit. The influence from the external environment on the Swedish pulp and paper industry is, thus, present and strong and has forced producers to activate their innovative potential, i.e. to start innovative initiatives outside their traditional business areas. However, the external influence has not come in the form of a threat from disruptive technology, but has rather served as a stimulus to activate the industry's endogenous innovation potential and in the end has supported industry endogenous innovation mechanisms. In sum, both cases of mature industries studied show that external shocks that disrupt the development logic of an industry or abandoning of existing resources are not the only source of innovation in mature industries and even in those cases where external influences exist, they can in fact serve to support industry endogenous innovation mechanisms.

All in all, the findings from the appended papers show that industry endogenous innovation mechanisms, in the form of reactive sequences and self-reinforcing mechanisms, can enable and sustain innovation in mature industries. The fact that it was possible to conceptualize industry endogenous innovation mechanisms via the analytical tools of the path dependency literature-one of the central parts of the hinders-focusing perspective on innovation in mature industries-has important implications for the understanding of innovation potential of mature industries. First, it implies that path dependent industries are not necessarily non-innovative and certainly not necessarily locked in to a single, non-optimal solution. On the contrary, both reactive sequences and all four types of self-reinforcing mechanisms have the potential to drive endogenous innovation. This further implies that path dependency can contribute to sustaining technological variety which, from the perspective of evolutionary economics, is a crucial prerequisite for continued industrial evolution (cf. Fagerberg 2003). 
Second, understanding that industry endogenous innovation mechanisms can be found among other (innovation-hindering) self-reinforcing mechanisms, which are characteristic for path dependent mature industries, is one step towards acknowledging that mature industries are neither unambiguously innovative (and in that case driven by endogenous innovation mechanisms) nor non-innovative (and in that case driven by innovation-hindering mechanisms). Instead, both sets of forces are present and affect mature industries at the same time and it is the balance between hindering and enabling forces that influences the innovative potential of mature industries. This confirms that the two existing perspectives on innovation in mature industries need to be combined since neither gives a comprehensive picture of all the processes affecting innovation alone. It also implies that in those cases when mature industries have managed to be highly innovative (i.e. when industry endogenous innovation mechanisms were present and strong), it is likely that certain innovation-hindering mechanisms also existed and needed to be overcome. In such cases, it is also important to realize that there was a "price" for overcoming those mechanisms, namely the innovation alternatives that could not be pursued. These issues will be considered in more detail when answering the third research question of the thesis.

\subsection{Company strategies that build upon industry endogenous innovation mechanisms}

The second research question of the thesis is concerned with the role of agency in the context of industry endogenous innovation mechanisms, and in particular, how exploitation strategy can be used to enable highly innovative outcomes. The results of the thesis suggest that, first, an expanded range of resources can be exploited in an industry driven by endogenous innovation mechanisms, and second, such an exploitation strategy can indeed lead to highly innovative outcomes.

In terms of the types of resources available and the ways in which they can be exploited, the results of the thesis show that established companies build on a wide range of existing resources while implementing their exploitation strategies. Across the two industry studies, five different types of resources were distinguished. Each type is presented below, accompanied by specific examples illustrating in what ways each particular resource was exploited.

First, established companies exploit resources that are under their direct control, i.e. those resources that are most commonly referred to in discussions of company resources. Paper 4 shows this exploitation using a product-process dichotomy and concludes that companies can build on both product and process-related knowledge. For example, some initiatives exploited existing product categories and the market positions associated with them, while other initiatives built on the understanding of the diversification potential of production processes that had already been 
implemented. Paper 5 considers the exploitation process from the perspective of different resource types and finds that existing raw materials, production plants, and technological competences were exploited by companies striving to develop new business.

Second, established companies exploit general attributes of their existing technologies or products. These are not specific to any particular company and cannot even be owned by companies, but are characteristic to the industry as a whole. For example, Paper 4 shows that a number of innovation initiatives pursued by established companies in the pulp and paper industry are aimed at providing more sustainable materials for existing applications. Examples include single-cell protein (an alternative to fishmeal, which is traditionally made from processed fish), insulation material (an alternative to polyurethane insulation materials), tall oil (an alternative to oil-based fuels) and carbon fibre (an alternative to fossil-based carbon fibre). The sustainability of forest-based products is largely an inherent feature of the raw material and can, therefore, be considered a shared-by-all resource to exploit. That the pulp and paper industry is by definition bio-based is often discussed as a general advantage of the industry when it comes to the challenge of transitioning to a bioeconomy, and that has become something of a hallmark of the pulp and paper industry in relation to its development of new materials and diversification into new business areas.

Further, Papers 4 and 5 highlight another example of resource exploitation in which general product attributes are exploited. In the Composite Material initiative, an important advantage of the material that was highly appreciated by potential customers was the "paper feel" that this new material provided. In this case, the producing company could exploit the tactile characteristics of the most traditional product in the pulp and paper industry, i.e. paper, when developing and commercializing new materials for novel applications unrelated to paper.

Third, companies exploit customers' preferences, needs, and competences. Paper 2 shows that the lighting industry is characterized by strong consumer preferences in favour of incandescent lamps-partly due to the characteristics of the light associated with them (e.g. colour rendering), and partly due to the long-term use of lighting fixtures that are compatible with those lamps. Although those preferences were inherently associated with innovation hinders at the adoption side, manufacturers could still exploit them when developing new lighting technologies: they adjusted the characteristics of both CFL and LED lamps to make them more similar to incandescent lamps in terms of visual appearance and light properties, and also with regard to their compatibility with existing fixtures. In the pulp and paper industry such exploitation of customers' preferences was not observed, which is explained by the nature of the innovation processes in that industry. 
Since companies diversified into new markets, they needed to take into account the preferences of customers in those new markets, which are essentially exogenous to the resource base of the focal pulp and paper industry.

Fourth, companies exploit their network relations across the whole value chain when developing novel products and processes. Paper 5 shows that innovation initiatives in the pulp and paper industry were built on active, and often long-term, collaborations with other manufacturers (e.g. through co-financing of research projects), and research institutes (via basic research programmes as well as project-specific partnerships).

Fifth, as a consequence of the active exploitation of network relations, companies can also exploit the resources of others in their innovation initiatives. Paper 4 finds that exploitation in one step of the value chain can enable newness in others. For example, some innovation initiatives involved the development of new products and/or new processes at the primary step, while the final step might remain unchanged. At the same time, some other initiatives exploited both existing products and processes during the primary step, but required new process and/or product development during the final step. Given that different steps in the value chain usually involve different actors, for the same innovation projects, some organizations can only exploit their resources (without developing any newness), while others innovate. For example, in the Shapeable Packaging initiative, the manufacturer concerned was able to exploit its existing products and processes, while new postprocessing technology was developed in a joint venture with the equipment producer. Further, in some initiatives (e.g. the Single-cell Protein initiative), the new knowledge developed by a research institute was combined with the exploitation of existing or modified manufacturing processes. In other cases (e.g. the Separation Technology initiative), manufacturers, in contrast, needed to develop new primary processes, which at the final stages would exploit an existing value chain.

Such "division of labour" in the innovation process may raise the concern that, for at least some of the organizations involved, these innovation initiatives might represent explorative rather than exploitative projects. Focusing on the role of manufacturers, Papers 4 and 5 show that even in those situations when manufacturers were the ones developing highly novel aspects in the projects studied (i.e. they were not involved in pure exploitation), they could still build on at least some of their existing resources. For example, the Carbon Fibre initiative required the manufacturer to alter both their products and their existing process, but all of those changes were still enabled by previously accumulated technological competence (e.g. knowledge of lignin characteristics). However, the thesis does not provide a detailed analysis of the roles of the other organizations 
involved, and further research is needed to investigate to what extent other types of actor (research institutes, equipment suppliers etc.) exploit their existing resources in situations when they also develop novel aspects.

The potential to exploit the resources of others uncovers the complexity of the innovation process in mature industries characterized by complex value chains. When innovation projects involve many organizations, each of which has a different role (e.g. some provide existing resources to exploit, others develop novel products or processes), it is not always clear who the real innovator in the system is. It is possible that manufacturers (the focus of this study) taking part in innovation initiatives do not directly participate in the development of novelty, which is at the core of every innovation process. At the same time, the evidence that exploitation of existing resources can enable novelty implies that even those actors who do not directly innovate in a particular project are still a crucial part of the innovation process as a whole and the absence of their existing resources could be as detrimental for the project outcomes as the absence of the innovators.

Different types and examples of resources exploited by companies in the lighting and pulp and paper industries are summarized in Table 7.

Table 7. Examples of resources exploited by companies in the lighting and pulp and paper industries.

\begin{tabular}{|l|l|}
\hline Resource type & Examples \\
\hline $\begin{array}{l}\text { Resources that are under a direct } \\
\text { control of companies }\end{array}$ & $\begin{array}{l}\text { Existing products, processes; raw materials, production plants, technological } \\
\text { competences (pulp and paper industry) }\end{array}$ \\
\hline $\begin{array}{l}\text { General attributes of existing } \\
\text { technologies or products }\end{array}$ & $\begin{array}{l}\text { Inherent sustainability of forest-based products, "paper feel" of forest-based } \\
\text { materials (pulp and paper industry) }\end{array}$ \\
\hline $\begin{array}{l}\text { Customers' preferences, needs, } \\
\text { competences }\end{array}$ & $\begin{array}{l}\text { Customers' preferences in favour of visual appearance and light properties of } \\
\text { incandescent bulbs (lighting industry) }\end{array}$ \\
\hline $\begin{array}{l}\text { Network relations } \\
\text { Resources of others }\end{array}$ & $\begin{array}{l}\text { Long-term collaborations of manufacturers with other manufacturers and research } \\
\text { institutes (pulp and paper industry) }\end{array}$ \\
\hline
\end{tabular}

The above overview of the different types of existing resources that are exploited by companies shows that although the first group of resources were traditional resource types directly controlled by firms, the other groups belonged to the overall characteristics of the industry, its structures and networks. This proves that, in the context of industry endogenous innovation mechanisms, companies can exploit an expanded range of different resources. 
With regard to the second aspect of the exploitation strategy in the context of industry endogenous innovation mechanisms - i.e. the potential to enable highly innovative outcomes - the thesis finds that the exploitation strategy can indeed enable major innovation. One indication of such positive influence from exploitation to innovative outcomes can be observed in the lighting industry study. Paper 1 shows that the patenting activities of the three leading lighting manufacturers exhibited a high level of technological persistence. All three companies retained high shares and patenting volumes in traditional lighting classes for a period of 35 years; patents in those traditional classes extensively referred to previous patents in the same classes; strong co-classification trends were found between the classes that represented incandescent and discharge technologies; and even up to $40 \%$ of the LED-related patents belonged to traditional lighting classes. This all indicates that existing technological knowledge was intensively exploited when developing new products and technologies. These patterns do not yet prove the enabling influence of exploitation efforts on innovative outcomes since patents can provide evidence of certain development patterns, but do not reveal the logic behind those patterns (e.g. whether it was exploitation or another factor that enabled innovation). However, the assumption that exploitation did indeed have an enabling influence on innovation in this case fits well with the findings of Paper 2, which shows that some innovation mechanisms, in the form of positive cross-technology externalities, built on reusing some of the characteristics of the incandescent technology. Retrofit LED products are an example of the outcomes of such efforts. Therefore, it can be suggested that the exploitation of technological competences contributed to the development of innovative products by leading lighting manufacturers.

Much more certain evidence of an enabling influence from the exploitation strategy to the development of highly innovative outcomes is found in the pulp and paper study. Paper 4 demonstrates that some innovation initiatives undertaken by established companies in the Swedish pulp and paper industry were driven by an ambition to exploit existing processes, which led to the development of products that were new to those companies or to the entire industry. Likewise, other innovation initiatives were driven by the ambition to exploit the existing products, which enabled the development of new processes. In both these types of exploitation, there was a clear enabling logic from existing products or processes to an innovative outcome; i.e. it was the exploitation of existing products or processes as such that justified and led to the development of new aspects. Further, Paper 5 shows that different resource types can have both a direct and an indirect enabling influence on the innovation outcomes of established companies. For example, in the pulp and paper industry, technological competences and network relations had a direct positive 
influence on the development of innovative initiatives, whereas raw materials, plants, and network relations mediated the influences from other resources by activating and strengthening the direct enabling influences and minimizing the hindering ones.

In summary, the above analysis shows that, in an industry driven by endogenous innovation mechanisms, companies can successfully implement an exploitation innovation strategy that enables highly innovative outcomes. Importantly, companies can exploit not only resources that are in their direct control, but also an expanded range of resources related to overall industry characteristics, structures, and networks.

\subsection{Impact of endogenous innovation mechanisms on the radicalness of outcomes}

The third research question addresses the potential limitations that the endogenous character of the underlying innovation mechanisms in mature industries can have on the range of innovation outcomes. The findings of the thesis show that such limitations do indeed exist, although they are not manifested in the exclusion of certain aspects of radicalness from the range of available opportunities, but rather in the necessity of making trade-offs with regard to how many and what particular aspects can be new at once.

The overview of examples of new technologies and products driven by industry endogenous innovation mechanisms, studied in Papers 1-5 (see Table 8), reveals that the innovations studied are radically new along different aspects, and the examples presented in the thesis cover all the theoretically considered aspects of radicalness. With regard to technological competence, each new technology considered in Papers 1-3 was based on a completely different principle of light generation-discharge and LED technologies are radically different from incandescent technology, and from each other. At the same time, the patent analysis in Paper 1 shows that radically new knowledge areas were combined with existing ones. As for the innovation initiatives in the pulp and paper industry, many also involved radically new technological knowledge. For example, the Composite Material initiative required competence in the properties of composite materials that was previously lacking, and the Carbon Fibre initiative was built on both lignin competence, which was already present in the industry, and carbon fibre competences, which needed to be newly developed. On the one hand, this fits the idea that the foundation of innovation requires the recombination of previously unconnected knowledge areas, but on the other hand, it implies certain limitations in itself. The latter point will be considered in more detail later in this section.

As for radical newness with regard to market competence, such examples were lacking in the lighting study, as new technologies were developed for the existing market. By contrast, the pulp 
and paper industry provided many such examples since the initiatives studied sought to diversify the business of established companies by adding applications and markets that did not relate to traditional business areas. Examples of such initiatives, described in Papers 4 and 5, include the Insulation Material and the Single-Cell Protein initiatives developed for the insulation and fishing markets, respectively.

Radicalness with regard to other resources could be observed in the lighting industry, where differences across technologies were also reflected in differences in the physical resources associated with them. For example, Paper 2 discusses large facilities that are specialized for each lighting technology. Further, some of the examples from the pulp and paper industry, discussed in Paper 5, demonstrate that various organizational characteristics-such as company culture or value chain position—needed to undergo a radical change (e.g. the Composite Material initiative).

With regard to the characteristics of the resulting product, Paper 4 shows that many initiatives in the pulp and paper industry were radically new along this aspect. Examples include the Single-Cell Protein and Separation Technology initiatives. In contrast, the development logic in the lighting industry, which was characterized by several types of self-reinforcing mechanisms, led to a similarity in product characteristics across technologies.

Radicalness in terms of new process characteristics was observed both in the examples in the lighting industry, where production processes were highly specialized, as well as in some examples in the pulp and paper industry that involved the development of completely new processes (e.g. the Separation Technology, Carbon Fibre and Nanocellulose initiatives).

Radicalness in terms of performance improvements along existing performance criteria could be clearly seen in the lighting industry. As shown in Paper 3, stable performance criteria existed across technologies, which could differ significantly in performance along some particular criteria. For example, the working life of fluorescent lamps is 20 times longer than that of conventional incandescent lamps, and LEDs have a working life of up to 50 times longer than incandescent bulbs. In contrast, when products for new markets with completely new characteristics were developed in the pulp and paper industry, innovations were radical in terms of new performance criteria. For example, the performance of the outcomes of the Insulation Material and Single-Cell Protein initiatives were compared with existing insulation and fish feed products, respectively, rather than with paper pulp. 
In sum, the above examples show that innovations driven by endogenous mechanisms can be radical along a wide range of different aspects. As expected, no innovation was simultaneously radical along all aspects. However, as a rule, more than one aspect was new in every case. Moreover, there was a logic to how these aspects were combined: radicalness in some aspects could be explained by radicalness in others. For example, in the pulp and paper industry market, competence radicalness was often combined with radically new product characteristics and the appearance of completely new performance criteria (e.g. for Single-Cell Protein and Insulation Material initiatives). This combination of aspects is quite logical considering that diversification, which took place in the pulp and paper industry, involves the development of products that are completely new to the industry, which forces manufacturers to enter new markets. As a consequence, the performance of the new products is judged along criteria accepted in that new market, which is why the set of performance criteria also differs considerably from those used to assess older products.

However, it is important to note that the interconnections between different aspects of radicalness are not universal for all innovations, but very specific. For example, in the lighting industry, technology competence radicalness was reflected in new process characteristics, as well as in radical newness related to other resources (for both fluorescent lighting and LED), whereas in the pulp and paper industry radically new technology competence could be well integrated with existing production processes (as in the Composite Material initiative described in Paper 4).

Table 8. Radicalness of technologies and initiatives studied in the thesis7

\begin{tabular}{|c|c|c|}
\hline \multirow{2}{*}{ Aspect of radicalness } & $\begin{array}{c}\text { Examples of radically new technologies } \\
\text { and products }\end{array}$ & $\begin{array}{c}\text { Examples of technologies and products } \\
\text { where radicalness was limited by the } \\
\text { exploitation logic }\end{array}$ \\
\hline \multirow{2}{*}{ Technology competence } & Fluorescent lighting \\
LED & Not found \\
\hline Market competence & Composite Material \\
& Carbon Fibre & Fluorescent Lighting \\
\hline
\end{tabular}

\footnotetext{
7 As well as the foregoing discussion, Table 8 references a selection of innovation initiatives studied in the course of the pulp and paper industry study. The choice of initiatives was made according to two main criteria. First, those new to the industry (rather than new to the company) were included. Further, for initiatives new to the industry, the changes in primary products and processes were considered in order to avoid confusion when using the value chain perspective that would include both primary and final steps.
} 


\begin{tabular}{|c|c|c|}
\hline & $\begin{array}{l}\text { Composite material } \\
\text { Carbon Fibre }\end{array}$ & \\
\hline Other resources & $\begin{array}{c}\text { Composite Material } \\
\text { Fluorescent lighting } \\
\text { LED }\end{array}$ & Basically all initiatives in pulp and paper \\
\hline Product characteristics & $\begin{array}{l}\text { Separation technology } \\
\text { Single-Cell Protein } \\
\text { Carbon Fibre } \\
\text { Composite Material }\end{array}$ & $\begin{array}{c}\text { Fluorescent Lighting } \\
\text { LED } \\
\text { Nanocellulose } \\
\text { Insulation Material }\end{array}$ \\
\hline Process characteristics & $\begin{array}{c}\text { Separation Technology } \\
\text { Carbon Fibre } \\
\text { Nanocellulose } \\
\text { Fluorescent lighting } \\
\text { LED }\end{array}$ & $\begin{array}{l}\text { Single-Cell Protein } \\
\text { Composite Material }\end{array}$ \\
\hline $\begin{array}{l}\text { Performance along } \\
\text { existing criteria }\end{array}$ & $\begin{array}{l}\text { Fluorescent lighting } \\
\text { LED }\end{array}$ & Not found \\
\hline $\begin{array}{c}\text { Performance along new } \\
\text { criteria }\end{array}$ & $\begin{array}{l}\text { Insulation Material } \\
\text { Single-Cell Protein } \\
\text { Composite material } \\
\text { Carbon fibre }\end{array}$ & $\begin{array}{l}\text { Fluorescent Lighting } \\
\text { LED } \\
\text { Nanocellulose }\end{array}$ \\
\hline
\end{tabular}

Although no particular aspect of radicalness was found less likely to be driven by endogenous innovation mechanisms, the findings from the thesis do indicate certain limits of the radicalness of innovations rooted in existing innovation mechanisms (see Table 8, Column 3). Paper 1 demonstrates that the lighting industry as a whole, and the three leading established companies in particular, are highly persistent with respect to the development of technological competence. As proof of this persistence, a patent analysis reveals that: traditional patent classes have remained significant for a period of 35 years; those classes have also been widely represented in LED-related patents; and in over $70 \%$ of the cases, patents refer to other patents that belong to the same technology. Similarly, Paper 2 shows that some of the positive cross-technology externalities (positioned in the thesis as endogenous innovation mechanisms) involve copying older technologies, which can also imply that more innovative options are not pursued.

Although technological persistence and the copying of older technologies did not directly diminish the technological radicalness of innovations in the lighting industry, the results of the thesis show that more radical innovations could have been developed if all the restrictions imposed by industry maturity could have been avoided. Thus, Paper 2 indicates that most innovative LED solutions were 
not pursued and implemented as actively as retrofit lamps because they would not have fit the current preferences and complementary assets of consumers. The successful imitation of incandescent lamps by fluorescent and LED technologies allowed those technologies to survive, but at the same time prevented the development of more radical product characteristics with novel performance criteria that would have required different market competences. Strong adoptionrelated self-reinforcing mechanisms in the lighting industry justified the choice of this strategy and also led to technological failure in those cases where other approaches were implemented (as in the case of fluorescent lighting before the adaptation process), but it is still important to acknowledge that this strategy had its price in terms of lower innovation levels for the aspects that were exploited.

Similarly, manufacturers in the pulp and paper industry made a conscious choice to not to pursue higher innovativeness in certain aspects in order to be able to exploit existing positions. For example, Papers 4 and 5 discuss the material nanocellulose, which can be used for a wide range of different applications. One of the companies interviewed for the study that had participated in this initiative made a strategic choice to pursue applications within the packaging business despite realising that there were also interesting opportunities for this material in other applications. This decision was justified by the company's desire to exploit existing product segments. Other innovations in the pulp and paper industry, e.g. the Single-Cell Protein initiative, were driven by the goal of exploiting existing processes; the results of the thesis show that this exploitation enabled innovations along certain aspects (e.g. market competence, product characteristics). However, the mere decision to avoid major modifications of the existing process led to a lower level of innovation with respect to this particular aspect.

These examples show that in both industries endogenous mechanisms led to limitations with regard to the innovativeness of outcomes across a variety of aspects. These limitations can be described in terms of trade-offs that manufacturers needed to make when deciding to pursue innovations based on the exploitation of existing resources and, consequently, were driven by industry endogenous innovation mechanisms. Such trade-offs imply that industry endogenous mechanisms do open valuable and potentially radical innovation opportunities (and the results of this thesis demonstrate this), but at the same time they limit certain other opportunities simply because the exploitation of some particular existing resource is prioritized over exploration of new resources.

Interestingly, just as logical connections between radically new aspects within the same examples were observed, connections between aspects that were strategically chosen to remain unchanged 
were also observed. As mentioned above, both LED and fluorescent lighting technology exploited existing product characteristics. As a consequence, radicalness in terms of new performance criteria, although theoretically possible, was not pursued because new technologies were viewed in the frame of existing, well established performance criteria. Another combination of retained criteria was characteristic to diversification initiatives in the pulp and paper industry. With only a few exceptions, the examples studied tended to retain production processes and other resources, while innovating in terms of market competences, product characteristics, and new performance criteria.8

This observation once again highlights the difference between the two case industries with respect to adoption-related characteristics. Thus, new lighting technologies targeted the existing market and existing customers, so those technologies were able to retain and build on an inter-connected group of market-related aspects (market competences, product characteristics, and existing performance criteria). These retained characteristics related to technology adoption also became the foundation for manufacturing-related endogenous innovation mechanisms in this industry. In contrast, diversification initiatives in the pulp and paper industry targeted new markets, which is why the market-related aspects appeared among those that were radically new in those initiatives, while other aspects (production process, technological competences, other resources) were retained and shaped the industry endogenous innovation mechanisms.

The interconnections observed between different aspects of radicalness have certain implications for understanding how the innovation process is driven by industry endogenous innovation mechanisms. Previous analysis showed that exploitation of certain resource types can enable newness with regard to other resource types and, as a consequence, radicalness along the aspects corresponding to those resources. The analysis in this section adds to those previous results by showing that the initial choice of resources or aspects to exploit may have further implications since: a) radically new aspects may lead to newness in other, related aspects; and b) exploitation of certain aspects may lead to the exploitation of other, related aspects.

The thesis also shows that the limiting effects of exploitation can be overcome over time via a succession of innovation initiatives with different combinations of radical vs retained aspects so that innovations that are radical along many aspects can also be driven by endogenous innovation

\footnotetext{
8 One exception is the Nanocellulose initiative in the pulp and paper industry, where the decision to use the new material in the existing products led not only to the exploitation of existing product characteristics, but also to a focus on existing performance criteria rather than an exploration of new performance criteria (which in theory could be an option with the nanocellulose material).
} 
mechanisms and an exploitation innovation strategy. While a particular initiative may not pursue radicalness along certain aspects as a consequence of an endogenous innovation logic, later initiatives can take advantage of the previous results to pursue radicalness along previously retained aspects. For example, Paper 4 discusses the Carbon Fibre initiative that resulted in newness along both product and process development aspects and throughout the whole value chain. However, the paper also shows that this initiative was rooted in a previous improvement in process efficiency, which could be seen as a pure exploitation of the existing process. This implies that innovations that are radical across many aspects can emerge from a chain of smaller-scale innovations that build on each other. Using the same logic, it can be suggested that in the lighting industry the establishment of LED retrofit lamps served as a first step that may in the future enable development and commercialization of more radical LED-based solutions.

To summarize the answer to the third research question, it can be concluded that the endogenous character of innovation mechanisms does not imply strict limitations with regard to any of the specific aspects of radicalness to be developed. On the contrary, different examples of innovation in the lighting and pulp and paper mature industries considered in the thesis together covered all the radicalness aspects identified in the theory section. However, limitations caused by the endogenous character of innovation mechanisms could be observed in the form of trade-offs between different aspects of new technologies and products. While the exploitation strategy enabled certain aspects to be radically new, it simultaneously produced limitations on newness in other aspects-those that had been explicitly chosen to be exploited as well as other aspects related to them. This implies that endogenously driven innovation processes have their price in the form of limited innovation levels along some innovation aspects, but they also have their reward in the form of enabled radicalness in others. 


\section{Discussion: interconnection between company strategies and industry}

\section{endogenous innovation mechanisms}

This thesis has addressed industry endogenous innovation processes at two levels: the level of industry-wide mechanisms and the level of company strategies. The processes at these two levels are interconnected: on the one hand, overall industry-level innovation mechanisms are to a certain extent the result of companies' choices; on the other hand, companies are influenced by industrylevel mechanisms when they formulate and implement their strategies.

Explaining this interconnection was not within the scope of the thesis and would in fact require a separate research project as doing so touches upon some fundamental issues with regard to innovation in companies and industries. However, as a result of the detailed investigation of each of these levels in turn, the thesis offers a number of observations about their interconnection, which can serve as a starting point for further investigation. These observations are presented below.

When it comes to understanding the influence of company strategies on overall industry mechanisms, it is important to bear in mind that, essentially, industry-level processes comprise a collection of choices made and actions taken by individual companies. As soon as a critical mass of such actions has been gathered and synergies between them have taken place, industry-level mechanisms represent an aggregated set of forces that are largely independent of any particular choice at any individual company. However, seeds or reflections of those choices, probably multiplied in the actions of other companies, do become part of the aggregated industry logic. Therefore, a crucial question here is how certain strategic choices by companies matter in and contribute to the process of formation of industry-level mechanisms.

With regard to answering this question, the findings of the thesis illustrate that similar strategic actions by a number of established companies can contribute to shaping industry-level mechanisms. Paper 2 shows the importance of development-related self-reinforcing mechanisms in driving endogenous innovation. Such mechanisms can be considered to be the result of strategic actions by manufacturers (in contrast to adoption-related mechanisms that are rooted in the choices of technology users). For example, the choice of manufacturers to adapt new technologies to imitate incandescent lamps or to fit existing fixtures initiated industry endogenous innovation mechanisms in the lighting industry, from which both new and incandescent technology benefited. Similarly, Paper 4 shows how the intention of several established companies in the pulp and paper industry to diversify their production processes and use existing process technologies as a foundation for the 
development of novel materials for new markets and applications shaped an industry-wide mechanism where the refinement and extension of the existing production process was able to reinforce existing products and businesses as well as new ones.

Despite these examples, the influence of company strategies on industry-level innovation mechanisms is not straightforward. Apart from the fact that far from all actions by companies can transform into industry-wide patterns, not all of the company-shaped mechanisms can be considered as innovation-enabling. Thus, Paper 2 demonstrates a number of development-related mechanisms in the lighting industry that can be characterized as positive feedbacks within one technology, which have negative externalities for other technologies (i.e. traditionally acknowledged self-reinforcing mechanisms associated in the literature with decreased levels of innovativeness). Examples include the establishment of testing and performance specifications for CFL lamps or sunk costs associated with technology-specialized production facilities and equipment. In addition, it is important to keep in mind that company strategies are not the only source of influence on industrylevel processes. Just to name a few examples, Paper 2 identifies a variety of technology-adoption self-reinforcing mechanisms (which were actually detrimental for innovation) and Paper 4 takes up the role of the external environment in activating innovation activities in the pulp and paper industry.

As for the opposite direction of mutual influence, industry-level mechanisms have feedback effects on the strategic options available to companies. The path dependency literature has been quite persuasive in showing that self-reinforcing mechanisms make certain choices-i.e. certain directions of further development-easier and more attractive to pursue. If we acknowledge that some of the self-reinforcing mechanisms can indeed bring about innovation, then industry endogenous innovation mechanisms would also provide certain alternatives that would fit better with exploitation and, therefore, would be more likely to be chosen by companies and potentially result in higher innovation levels. This kind of influence raises the question of to what extent companies are free to formulate and implement their own strategies and to what extent they just follow the logic of industry development. There, some arguments in favour of companies' ability to act independently have been gathered by the proponents of path creation theory, which suggest that companies are able to break with industry mechanisms. Therefore, to the extent that the choice of following particular industry mechanisms (including innovation ones) is conscious and explicitly articulated in a company's strategic decision making, even the act of following an industry mechanism can be considered as an active rather than a passive choice. What remains unclear, however, is to what extent industry mechanisms provide companies with alternatives that are 
attractive to pursue and promising from an innovation perspective and to what extent companies are conscious of the origins and the consequences of those alternatives (i.e. whether they just follow the path or make an active strategic judgement).

The findings of the thesis demonstrate that industry mechanisms do make certain development options easier to pursue and, as a result, become reflected in the strategies of individual companies in the industry. At the same time, companies seem to follow these mechanisms rather consciously, i.e. by considering different alternatives and making an active choice to pursue those "suggested" alternatives rather than passively following them. For example, Paper 3 discusses the development of LED technology in the lighting industry and shows that an awareness of the potential of this technology was present in the industry several decades before it became a viable alternative to other lighting sources. This implies that an industry-level mechanism established the understanding among manufacturers that the LED path was worth pursuing. At the same time, the interviews with lighting manufacturers show that the decision to develop LED lighting was based on thorough strategic considerations that involved a series of repeated technology assessments over the years, in which the current potential and technology readiness were estimated at each point in time. Similarly, Paper 2 discusses the process of development of retrofit LED lamps in the lighting industry as a result of a broader cross-technology innovation mechanism of adapting newer technologies to copy the characteristics of incandescent bulbs. This is one more example in which manufacturers pursued the development option "suggested" by industry mechanisms. Moreover, in this case complying with the industry mechanism had proven to be previously successful-i.e. in the adaptation of CFL lamps. However, instead of passively following the established pattern of action, the manufacturers proved to be well aware of alternative solutions, but consciously pursued the retrofit option (along with other development alternatives for LEDs) as the one for which consumers were ready at that particular moment. As one of the interviewees put it: "To basically hide the new technology and disguise it in a way to make it attractive for people to buy it - this is a kind of a product design technology challenge."

In summary, various examples of interaction between the company strategies and industry-wide mechanisms show that the processes on these two levels can mutually reinforce each other. However, as highlighted above, a lot of gaps still remain with regard to understanding these interactions. For example, to what extent is a well-functioning interaction between the two levels a prerequisite for innovations to be successfully developed and commercialized in mature industries? What happens if certain innovation-promising alternatives (those "suggested" by industry endogenous innovation mechanisms) are not picked up and pursued by companies and what might 
the reasons be for this? Further, what does the balance between the two directions of mutual influence look like and how does it change over time? It appears that industry-level mechanisms are initially shaped by company strategies, but at some point those mechanisms become sufficiently self-sustaining to start affecting strategic decisions taken by individual companies in their turn. How, when, and under the influence of what factors does this change of balance take place? These are examples of the issues that require attention in further research. 


\section{Conclusions}

This thesis aimed to systematically address, explain, and conceptualize industry endogenous innovation and its driving mechanisms in mature industries. The results of the thesis-achieved by answering three more specific research questions-led to a number of main conclusions.

First, the major conclusion of the thesis is that innovations of any magnitude can be endogenously developed in mature industries. This conclusion has two closely interrelated, yet distinct aspects. On the one hand, in contrast to the assumption generated by the hinders-focusing perspective on innovation in mature industries, it implies that a disruptive external shock or a break with the past are not the only sources of major change in such industries. On the other hand, the thesis not only shows that more-than-incremental improvements can be endogenously enabled, but also explicitly highlights that radical innovation of any aspect discussed in the theory can be endogenously developed in mature industries.

Second, the thesis suggests that at the industry level endogenous innovation is driven by innovation mechanisms that can be conceptualized as reactive sequences and self-reinforcing mechanisms. Reactive sequences in the form of the same driving forces (yet differing development patterns) behind, on the one hand, existing technologies and products and, on the other hand, new ones played the role of endogenous mechanisms that enabled innovation in both lighting and pulp and paper industries. Further, self-reinforcing mechanisms in the form of common development logic and common development patterns played the role of industry endogenous mechanisms that could both enable (in the pulp and paper industry) and sustain (in the lighting industry) innovation. Such innovation enabling self-reinforcing mechanisms took the form of positive externalities, i.e. positive non-competitive cross-technology or cross-product interactions that reinforced all the technologies or products affected.

Third, at the level of individual companies, the exploitation strategy corresponds to the logic of industry endogenous innovation mechanisms. This implies that exploitation has an enabling influence on highly innovative outcomes, and at the same time this strategy builds on a wide range of resources available in the industry, including not only those directly controlled by a company, but also general technology and product attributes, the preferences of existing customers as well as the resources of others.

Fourth, while industry endogenous mechanisms do enable radical innovation, they also impose certain limitations on the radicalness of the outcomes. Importantly, those limitations do not imply 
that achieving radicalness along some particular aspects is impossible. Instead, limitations come in the form of trade-offs in terms of how many and what particular aspects can be radically new at once. Thus, the decision to exploit and retain certain aspects enables radicalness along some other aspects, but at the same leads to the retention (and hence reduced novelty) of some additional aspects related to those that were initially chosen to be exploited.

\subsection{Contributions and suggestions for future research}

By increasing understanding of endogenous innovation in mature industries and its underlying mechanisms, this thesis contributes to creating a more balanced overall perspective on the innovation potential of mature industries.

As shown in the introduction to the thesis, current research contains two partially contradictory perspectives: the first one focuses on innovation hinders and therefore largely underestimates the innovation potential of mature industries, while the second perspective, although more optimistic, has so far lacked systematization and an understanding of the mechanisms that drive endogenous innovation. The results of the thesis contribute to resolving this contradiction. First, clear evidence of the potential of mature industries to endogenously enable and sustain radical innovation shows that the hinders-focusing perspective alone is incomplete and needs to be complemented with explanations that address this potential. Second, the conceptualization of industry endogenous innovation mechanisms, provided in the thesis, contributes to strengthening the second perspective by presenting a systematic analysis of the logic behind endogenous innovation. Third, the thesis provides evidence that industry endogenous innovation mechanisms are rooted in the same processes that can be viewed as innovation hindering, i.e. both types of processes represent different kinds of self-reinforcing mechanism. This draws attention to the fact that innovation hindering and innovation enabling mechanisms co-exist and need to be considered in combination.

Therefore, the results of the thesis can be considered as a step towards integrating the two perspectives on the innovation potential in mature industries. Having such a unified, integrated perspective that takes into account both innovation hindering and innovation enabling mechanisms allows the character of further discussions of innovation potential of mature industries to be changed. Instead of arguing about whether mature industries in general have the potential to develop radical innovation, the focus can be shifted to when or under what conditions radical innovation can be endogenously developed. A joint analysis of innovation hindering and innovation enabling mechanisms can suggest if in each particular case innovation enabling mechanisms are strong enough in relation to innovation hindering ones to allow for radical innovations. 
In addition, the thesis contributes to further development of two concepts that have been actively used in both theoretical discussions and analysis-namely, the concepts of path dependency and exploitation. With regard to path dependency, the thesis contributes to a deepening of the understanding of self-reinforcing mechanisms and reactive sequences. Both types of processes were shown to lead to highly innovative outcomes, which was not considered in previous research. Furthermore, a new type of self-reinforcing mechanisms (i.e. cross-technology positive externality) was conceptually established and empirically studied.

The contribution to the conceptualization of exploitation innovation strategy comes in the form of a justification of the enabling influence of this strategy on innovative outcomes. Taking into account the ongoing debate about the magnitude of innovation that can result from exploitation (cf. Li, Vanhaverbeke et al. 2008, Bauer and Leker 2013), the results of the thesis provide valuable evidence that exploitation can enable radical innovation.

Together with providing answers to the questions posed in the thesis, the results open for new questions and new research avenues. One direction for future research needs to build on the understanding that industry endogenous innovation mechanisms exist and can lead to highly innovative outcomes. In this regard, additional empirical evidence needs to be gathered in order to capture more detailed patterns behind such mechanisms. For example, a study of the role of selfreinforcing mechanisms in sustaining technological variety in industries other than lighting would serve to refine the understanding of positive cross-technology externalities by, e.g., expanding the range of examples with demand-side innovation mechanisms. Further, the lighting and the pulp and paper industries suggested particular types of driving forces that might be behind innovation enabling reactive sequences-namely, variety of performance criteria and applications and continued development of core technological competence. Further empirical studies will help to establish what additional driving forces may exist and to what extent they can be generalized to other mature industries. In a similar vein, the patterns of interconnections between different aspects of radicalness, discussed with regard to the third research question of the thesis, might be studied in other empirical contexts to reveal what aspects tend to become new or stay unchanged together and what factors may affect those relations.

Another direction for future research relates to the interconnection between the two levels of endogenous innovation processes: the level of industry mechanisms and the level of company strategies. As section 6 discussed, there remain a number of unanswered questions with regard to this interconnection. For example, further studies need to take a closer look at how this 
interconnection evolves over time, concentrating on whether and why at some point the influence of industry level mechanisms on company level strategies becomes stronger than the influence flowing in the opposite direction and how companies can take that into account in their strategies.

Finally, the findings with regard to the multi-organizational character of innovation initiatives in the pulp and paper industry show that the "division of labour" between companies across the value chain in terms of exploration and exploitation needs to be investigated further. The results showed that in such collaborative projects manufacturers can either exploit their resources while others explore new aspects, or combine exploitation and exploration. However, a deeper understanding of the roles of other types of actors (e.g., research institutes, equipment suppliers, customers etc.) is needed to create a more complete understanding of the overall logic that enables and drives innovation in this kind of project as well as the distribution of exploration vs exploitation activities across all involved actors.

\subsection{Managerial implications}

The thesis provides evidence of the high innovation potential in mature industries as well as explains industry- and company-level processes that can enable and drive endogenous innovation. Therefore, the results of the thesis suggest a number of recommendations to managers in established companies in mature industries of how they can take advantage of industry endogenous mechanisms while at the same time avoiding the pitfalls associated with innovation hindering forces. Key managerial implications are formulated below.

First, the understanding that both innovation enabling and innovation hindering mechanisms affect mature industries simultaneously implies that companies need to develop balanced strategies that neither entirely "break with the past" (which will eliminate the possibility of taking advantage of industry endogenous innovation mechanisms), nor blindly follow industry endogenous logic (which may result in lock-in if innovation hindering mechanisms are followed). Instead, a balanced strategy allows companies to critically evaluate the various development alternatives, analyse why it seems easier or more attractive to follow some of them, and what the implications for innovation may be.

Second, managers in established companies who decide to pursue the exploitation innovation strategy need to systematically address a whole set of available resources in order to be able to exploit them and the interconnections between them in the most beneficial way possible. This involves a number of interlinked decisions and choices: 
(1) The decision about what resources to build on is crucial for the whole innovation process. While the chosen resource is associated with the company's strength and competitive advantage, exploitation of it implies that this particular aspect of a new technology or product will not be radically new.

(2) Since exploitation of some resource types enables radicalness with regard to other resources or aspects, the interconnections between the resource chosen in decision (1) and other resource types need to be analysed in order to understand what aspects of a new technology or product the resource chosen in decision (1) enables to be radically new.

(3) Since radicalness along some aspects is often combined with radicalness along other, related aspects, further analysis needs to be carried out to reveal which other aspects of a new technology or product can also be radically new as a result of decision (2).

(4) Since the exploitation of some resource types leads to exploitation and, hence, lower novelty with regard to other, related resource types or aspects, further analysis needs to be undertaken to discover which other aspects will be retained as a result of decision (1).

Third and finally, managers in established companies need to take into account that the range of resources available to exploit is not limited to resources directly controlled by a company. Apart from these, the resource range also includes common technology and product attributes, shared resources as well as the resources of others, which can be accessed via network relations with other actors across the value chain. 


\section{List of References}

Abernathy, W. J. and J. M. Utterback (1978). "Patterns of innovation in technology." Technology review 80(7): 40-47.

Adams, S. B. (2011). "Growing where you are planted: Exogenous firms and the seeding of Silicon Valley." Research Policy 40(3): 368-379.

Adner, R. (2002). "When Are Technologies Disruptive? A Demand-Based View of the Emergence of Competition." Strategic Management Journal 23(8): 667-688.

Adner, R. and D. Levinthal (2001). "Demand Heterogeneity and Technology Evolution: Implications for Product and Process." Management Science 47(5): 611-628.

ALG (2012). Evolution of the Incandescent Lamp, ALG Connections.

https://algonline.org/pdf/ALGConnections EvolutionofIncandescent Final.pdf.

Anderson, P. and M. L. Tushman (1990). "Technological Discontinuities and Dominant Designs: A Cyclical Model of Technological Change." Administrative Science Quarterly 35: 604-633.

Antonelli, C. (2009). "The economics of innovation: From the classical legacies to the economics of complexity." Economics of Innovation and New Technology 18(7): 611-646.

Araujo, L. and D. Harrison (2002). "Path Dependence, Agency and Technological Evolution." Technology Analysis \& Strategic Management 14(1): 5-19.

Arend, R. J. (1999). "Emergence of entrepreneurs following exogenous technological change." Strategic Management Journal 20(1): 31-47.

Arrow, K. J. (1962). Economic Welfare and the Allocation of Resources for Inventions. The Rate and Direction of Inventive Activity: Economic and Social Factors. R. Nelson. Princeton, Princeton University Press: 609-626.

Arthur, W. B. (1989). "Competing Technologies, Increasing Returns, and Lock-In by Historical Events." The Economic Journal 99(394): 116-131.

Arthur, W. B. (1994). Increasing returns and path dependence in the economy. Ann Arbor, MI, University of Michigan Press.

Arthur, W. B. (1996). "Increasing Returns and the New World of Business." Harvard Business Review(JulyAugust): 100-109.

Backlund, B. and M. Nordström (2014). Nya produkter från skogsråvara. En översikt av läget 2014, Innventia. Innventia Rapport nr. 577.

Barney, J. (1991). "Firm resources and sustained competitive advantage." Journal of Management 17(1): 99-120.

Bauer, M. and J. Leker (2013). "Exploration and exploitation in product and process innovation in the chemical industry." R\&D Management 43(3): 196-212.

Benner, M. J. and M. L. Tushman (2003). "Exploitation, exploration, and process management: The productivity dilemma revisited." Academy of management review 28(2): 238-256.

Bergek, A., C. Berggren, T. Magnusson and M. Hobday (2013). "Technological discontinuities and the challenge for incumbent firms: Destruction, disruption or creative accumulation?" Research Policy 42(67): 1210-1224.

Bergek, A., S. Jacobsson, B. Carlsson, S. Lindmark and A. Rickne (2008). "Analyzing the functional dynamics of technological innovation systems: A scheme of analysis." Research Policy 37(3): 407-429. Berggren, C., T. Magnusson and D. Sushandoyo (2015). "Transition pathways revisited: Established firms as multi-level actors in the heavy vehicle industry." Research Policy 44(5): 1017-1028.

Borghei, B. and T. Magnusson (2016). "Niche experiments with alternative powertrain technologies: the case of electric city-buses in Europe."Int. J. Automotive Technology and Management Article in Press. Breschi, S., F. Lissoni and F. Malerba (2003). "Knowledge-relatedness in firm technological diversification." Research Policy 32(1): 69-87. 
Breschi, S., F. Malerba and L. Orsenigo (2000). "Technological Regimes and Schumpeterian Patterns of Innovation." The Economic Journal 110(463): 388-410.

Brusoni, S. and G. Sgalari (2006). "New combinations in old industries." Journal of Evolutionary Economics 16(1-2): 25-43.

Caiazza, R. (2015). "Explaining innovation in mature industries: evidences from Italian SMEs." Technology Analysis \& Strategic Management 27(8): 975-985.

Carlsson, B. and G. Eliasson (2003). "Industrial dynamics and endogenous growth." Industry and Innovation 10(4): 435-456.

Castaldi, C. and S. Sapio (2006). The properties of sectoral growth: Evidence from four large european economies, Groningen Growth and Development Centre, University of Groningen.

Castiaux, A. (2007). "Radical innovation in established organizations: Being a knowledge predator." Journal of Engineering and Technology management 24(1): 36-52.

Cattani, G. (2005). "Preadaptation, firm heterogeneity, and technological performance: a study on the evolution of fiber optics, 1970-1995." Organization Science 16(6): 563-580.

Chandy, R. K. and G. J. Tellis (2000). "The incumbent's curse? Incumbency, size, and radical product innovation." Journal of marketing 64(3): 1-17.

Christensen, C. M. (1992). "Exploring the limits of the technology S-curve. Part I: component technologies." Production and Operations Management 1(4): 334-357.

Christensen, C. M. and J. L. Bower (1996). "CUSTOMER POWER, STRATEGIC INVESTMENT, AND THE FAILURE OF LEADING FIRMS." Strategic Management Journal 17(3): 197-218.

Christensen, C. M. and R. S. Rosenbloom (1995). "Explaining the attacker's advantage: Technological paradigms, organizational dynamics, and the value network." Research Policy 24(2): 233-257. Cowan, R. and P. Gunby (1996). "Sprayed to Death: Path Dependence, Lock-in and Pest Control Strategies." The Economic Journal 106(436): 521-542.

Danneels, E. (2002). "The dynamics of product innovation and firm competences." Strategic Management Journal 23(12): 1095-1121.

David, P. A. (1985). "Clio and the Economics of QWERTY." The American Economic Review 75(2): 332 337.

Deniozos, D. (1994). "Steps for the introduction of technology management in developing economies: the role of public governments." Technovation 14(3): 197-203.

Dobusch, L. and J. Kapeller (2013). "Striking new paths: Theory and method in path dependence research." Schmalenbach Business Review 65: 288-311.

Dobusch, L. and Schüssler (2012). "Theorizing path dependence: a review of positive feedback mechanisms in technology markets, regional clusters, and organizations " Industrial and Corporate Change 22(3): 617-647.

Dosi, G. (1982). "Technological paradigms and technological trajectories: A suggested interpretation of the determinants and directions of technical change." Research Policy 11(3): 147-162.

Dosi, G. and R. R. Nelson (2010). "Technical change and industrial dynamics as evolutionary processes." Handbook of the Economics of Innovation 1: 51-127.

Ehrnberg, E. (1995). "On the definition and measurement of technological discontinuities." Technovation 15(7): 437-452.

Eisenhardt, K. M. (1989). "Building Theories from Case Study Research." Academy of Management

Review 14(4): 532-550.

Eisenhardt, K. M. and M. E. Graebner (2007). "Theory building from cases: Opportunities and challenges." Academy of Management Journal 50(1): 25-32.

Enkel, E. and O. Gassmann (2010). "Creative imitation: exploring the case of cross-industry innovation." R\&d Management 40(3): 256-270. 
Essletzbichler, J. and L. Winther (1999). "Regional technological change and path dependency in the Danish food processing industry." Geografiska Annaler, Series B: Human Geography 81(3): 179-196. Fagerberg, J. (2003). "Schumpeter and the revival of evolutionary economics: an appraisal of the literature." Journal of Evolutionary Economics 13(2): 125-159.

Fai, F. and N. Von Tunzelmann (2001). "Industry-specific competencies and converging technological systems: evidence from patents." Structural change and economic dynamics 12(2): 141-170.

Fai, F. M. (2003). Corporate Technological Competence and the Evolution of Technological

Diversification. Cheltenham, Edward Elgar.

Farrell, J. and G. Saloner (1985). "Standardization, compatibility, and innovation." The RAND Journal of Economics 16(1): 70-83.

Frishammar, J., U. Lichtenthaler and M. Kurkkio (2012). "The front end in non-assembled product development: A multiple case study of mineral-and metal firms." Journal of Engineering and Technology Management 29(4): 468-488.

Galunic, D. C. and S. Rodan (1998). "Research notes and communications: resource recombinations in the firm: knowledge structures and the potential for Schumpeterian innovation." Strategic management journal 19(12): 1193-1201.

Garcia, R. and R. Calantone (2002). "A critical look at technological innovation typology and innovativeness terminology: a literature review." Journal of product innovation management 19(2): 110132.

Garud, R., A. Kumaraswamy and P. Karnøe (2010). "Path dependence or path creation?" Journal of Management Studies 47(4): 760-774.

Geels, F. W. (2006). "The hygienic transition from cesspools to sewer systems (1840-1930): the dynamics of regime transformation." Research Policy 35(7): 1069-1082.

Global Industry Analysts (2011). Lamps - a global strategic business report, Global Industry Analysts, Inc. Granstrand, O. and S. Alänge (1995). "The evolution of corporate entrepreneurship in Swedish industry -was Schumpeter wrong?" Journal of Evolutionary Economics 5: 133-156.

Granstrand, O. and S. Sjölander (1990). "Managing innovation in multi-technology corporations."

Research Policy 19(1): 35-60.

Grant, R. M. (1991). "The resource-based theory of competitive advantage: implications for strategy formulation." California management review 33(3): 114-135.

Helfat, C. E. and M. B. Lieberman (2002). "The birth of capabilities: market entry and the importance of pre-history." Industrial and Corporate Change 11(4): 725-760.

Helfat, C. E. and M. A. Peteraf (2003). "The dynamic resource-based view: capability lifecycles." Strategic Management Journal 24: 997-1010.

Henderson, R. M. and K. B. Clark (1990). "Architectural Innovation: The Reconfiguration of Existing Product Technologies and the Failure of Established Firms." Administrative Science Quarterly 35: 9-30. Henning, M., E. Stam and R. Wenting (2013). "Path Dependence Research in Regional Economic Development: Cacophony or Knowledge Accumulation?" Regional Studies.

Herrmann, A., T. Tomczak and R. Befurt (2006). "Determinants of radical product innovations." European Journal of Innovation Management 9(1): 20-43.

Hill, C. W. L. and F. T. Rothaermel (2003). "The performance of incumbent firms in the face of radical technological innovation." Academy of Management Review 28(2): 257-274.

IEA (2006). Light's Labour's Lost. Policies for Energy-efficient Lighting. Paris Cedex, OECD/IEA.

Karnøe, P. and R. Garud (2000). Path Creation and Dependence in the Danish Wind Turbine Field. The Social Construction of Industries and Markets Oxford, Pergamon Press.

Katila, R. and G. Ahuja (2002). "Something old, something new: A longitudinal study of search behavior and new product introduction." Academy of Management Journal 45(6): 1183-1194. 
Katz, M. L. and C. Shapiro (1985). "Network externalities, competition, and compatibility." The American economic review: 424-440.

King, A. A. and C. L. Tucci (2002). "Incumbent entry into new market niches: The role of experience and managerial choice in the creation of dynamic capabilities." Management science 48(2): 171-186.

Klepper, S. (1997). "Industry Life Cycles." Industrial and Corporate Change 6(1): 145-181.

Klepper, S. and K. L. Simons (2000). "Dominance by birthright: entry of prior radio producers and competitive ramifications in the US television receiver industry." Strategic Management Journal 21(1011): 997-1016.

Koch, J., M. Eisend and A. Petermann (2009). "Path dependence in decision-making processes: Exploring the impact of complexity under increasing returns." BuR-Business Research 2(1): 67-84.

Kurkkio, M. (2011). "Managing the fuzzy front-end: insights from process firms." European Journal of Innovation Management 14(2): 252-269.

Leonard-Barton, D. (1992). "Core Capabilities and Core Rigidities: A Paradox in Managing New Product Development." Strategic Management Journal 13(S1): 111-125.

Li, Y., X. Li, Y. Liu and B. R. Barnes (2011). "Knowledge communication, exploitation and endogenous innovation: The moderating effects of internal controls in SMEs." $R$ and D Management 41(2): 156-172. $\mathrm{Li}, \mathrm{Y} ., \mathrm{W}$. Vanhaverbeke and W. Schoenmakers (2008). "Exploration and exploitation in innovation: Reframing the interpretation." Creativity and innovation management 17(2): 107-126.

Linton, J. D. and S. T. Walsh (2008). "A theory of innovation for process-based innovations such as nanotechnology." Technological Forecasting and Social Change 75(5): 583-594.

Louçã, F. (2014). "The elusive concept of innovation for Schumpeter, Marschak and the early econometricians." Research Policy 43(8): 1442-1449.

Mahoney, J. (2000). "Path Dependence in Historical Sociology." Theory and Society 29(4): 507-548. Malerba, F. and L. Orsenigo (1996). "Schumpeterian patterns of innovation are technology-specific." Research policy 25(3): 451-478.

March, J. G. (1991). "Exploration and exploitation in organizational learning." Organization Science 2(1): 71-87.

Mazzoleni, R. (1997). "Learning and path-dependence in the diffusion of innovations: Comparative evidence on numerically controlled machine tools." Research Policy 26(4-5): 403-428.

McGahan, A. M. and B. S. Silverman (2001). "How does innovative activity change as industries mature?" International Journal of Industrial Organization 19(7): 1141-1160.

McKinsey\&Company (2011). Lighting the way: Perspectives on the global lighting market. T.

Baumgartner, Wunderlich, F., Wee, D., McKinsey \& Company, Inc.

McMahon, D. and H. Thorsteinsdóttir (2013). "Pursuing endogenous high-tech innovation in developing countries: A look at regenerative medicine innovation in Brazil, China and India." Research Policy 42(4): 965-974.

Menanteau, P. and H. Lefebvre (2000). "Competing technologies and the diffusion of innovations: the emergence of energy-efficient lamps in the residential sector." Research Policy 29(3): 375-389.

Methé, D., A. Swaminathan and W. Mitchell (1996). "The underemphasized role of established firms as the sources of major innovations." Industrial and Corporate Change 5(4): 1181-1203.

Murmann, P. and F. Koen (2002). Towards a Systematic Framework for Research on Dominant Designs, Technological Innovations, and Industrial Change. Papers on Economics \& Evolution. Jena, Max Planck Institute for Research into Economic Systems.

Nagarajan, A. and W. Mitchell (1998). "Evolutionary diffusion: Internal and external methods used to acquire encompassing, complementary, and incremental technological changes in the lithotripsy industry." Strategic Management Journal 19(11): 1063-1077. 
Novotny, M. and S. Laestadius (2014). "Beyond papermaking: technology and market shifts for woodbased biomass industries - management implications for large-scale industries." Technology Analysis \& Strategic Management 26(8): 875-891.

OECD/IEA (2010). Transforming global markets for clean energy products. Energy efficient equipment, vehicles and solar photovoltaics. Paris Cedex, International Energy Agency.

Onufrey, K. (2014). Technology Dynamics in Multi-Technology Industries: Selection and Variety Creation through the Lens of Path Dependency and Path Generation Licentiate Thesis, Linköping University.

Page, S. E. (2006). "Path dependence." Quarterly Journal of Political Science 1(1): 87-115.

Pierson, P. (2000). "Increasing returns, path dependence, and the study of politics." American political science review 94(2): 251-267.

Porter, M. E. (1980). Competitive strategy: Techniques for analyzing industries and competitors. New York, The Free Press.

Romer, P. M. (1994). "The origins of endogenous growth." The journal of economic perspectives 8(1): 3-

22.

Rosenkopf, L. and A. Nerkar (2001). "Beyond local search: boundary-spanning, exploration, and impact in the optical disk industry." Strategic Management Journal 22(4): 287-306.

Rothaermel, F. T. and D. L. Deeds (2004). "Exploration and exploitation alliances in biotechnology: A system of new product development." Strategic management journal 25(3): 201-221.

Rynes, S. and R. P. Gephart Jr (2004). "Qualitative research and the Academy of Management Journal." Academy of Management Journal 47(4): 454-462.

Sandén, B. A. and K. M. Hillman (2011). "A framework for analysis of multi-mode interaction among technologies with examples from the history of alternative transport fuels in Sweden." Research Policy 40(3): 403-414.

Sanderson, S. W. and K. L. Simons (2014). "Light emitting diodes and the lighting revolution: The emergence of a solid-state lighting industry." Research Policy 43(10): 1730-1746.

Sanderson, S. W., K. L. Simons, J. L. Walls and Y. Lai (2008). Lighting. Innovation in Global Industries: US Firms Competing in a New World (Collected Studies). J. T. Macher and D. C. Mowery. Washington, D.C., The National Academic Press.

Sandström, C. G. (2014). Var skapades Sveriges 100 främsta innovationer?, Reforminstitutet.

Schienstock, G. (2007). "From path dependency to path creation: Finland on its way to the knowledgebased economy." Current Sociology 55(1): 92-109.

Schneiberg, M. (2007). "What's on the path? Path dependence, organizational diversity and the problem of institutional change in the US economy, 1900-1950." Socio-Economic Review 5(1): 47-80.

Schumpeter, J., Ed. (1934). The Theory of Economic Development. Cambridge, Mass., Harvard University Press.

Schumpeter, J. A. (1942/1994). Capitalism, Socialism \& Democracy. New York, Routledge. Siggelkow, N. (2007). "Persuasion with case studies." Academy of Management Journal 50(1): 20-24. Silverman, B. S. (2004). "Documentation for International Patent Classification - U.S. SIC concordance." Retrieved 10.05, 2012, from http://www.rotman.utoronto.ca/ silverman/ipcsic/documentation IPCSIC concordance.htm.

Smink, M. M., M. P. Hekkert and S. O. Negro (2015). "Keeping sustainable innovation on a leash? Exploring incumbents' institutional strategies." Business Strategy and the Environment 24(2): 86-101. Sosa, M. L. (2009). "Application-specific R\&D capabilities and the advantage of incumbents: Evidence from the anticancer drug market." Management science 55(8): 1409-1422.

Stack, M. and M. P. Gartland (2003). "Path creation, path dependency, and alternative theories of the firm." Journal of Economic Issues 37(2): 487-494.

Storz, C. (2008). "Dynamics in innovation systems: Evidence from Japan's game software industry." Research Policy 37(9): 1480-1491. 
Sydow, J., G. Schreyögg and J. Koch (2009). "Organizational path dependence: opening the black box." Academy of Management Review 34(4): 689-709.

Teece, D. J. (1986). "Profiting from technological innovation: Implications for integration, collaboration, licensing and public policy." Research Policy 15: 285-305.

Teece, D. J., G. Pisano and A. Shuen (1997). "Dynamic capabilities and strategic management." Strategic Management Journal 18(7): 509-533.

TheFreeDictionary (2016).

Thompson, P. (2005). "Selection and firm survival: evidence from the shipbuilding industry, 1825-1914." Review of Economics and Statistics 87(1): 26-36.

Tripsas, M. (1997). "Unraveling the process of creative destruction: complementary assets and incumbent survival in the typesetter industry." Strategic Management Journal 18(Summer Special Issue): 119-142.

Tripsas, M. (2008). "Customer preference discontinuities: A trigger for radical technological change." Managerial and decision economics 29(2-3): 79-97.

Trott, P. (2008). Innovation management and new product development. Harlow, Pearson education. Tushman, M. and P. Anderson (1986). "Technological Discontinuities and Organizational Environments." Administrative Science Quarterly 31: 439-465.

Utterback, J. M. (1974). "Innovation in Industry and the Diffusion of Technology." Science 183(4125): 620-626.

Utterback, J. M., and and W. J. Abernathy (1975). "A Dynamic Model of Process and Product Innovation." OMEGA, the Int. Jl of Mgmt Sci. 3(6): 639-656.

Vergne, J. P. and R. Durand (2010). "The missing link between the theory and empirics of path dependence: Conceptual clarification, testability issue, and methodological implications." Journal of Management Studies 47(4): 736-759.

Wang, C.-H. and L.-C. Hsu (2014). "Building exploration and exploitation in the high-tech industry: The role of relationship learning." Technological Forecasting and Social Change 81: 331-340.

Woodside Capital Partners International (2012). Research Report: LED Lighting. Palo Alto, CA, Woodside Capital Partners International.

Wu, B., Z. Wan and D. A. Levinthal (2014). "Complementary assets as pipes and prisms: Innovation incentives and trajectory choices." Strategic Management Journal 35(9): 1257-1278. 


\section{Papers}

The articles associated with this thesis have been removed for copyright reasons. For more details about these see:

http://urn.kb.se/resolve? urn:nbn:se:liu:diva-136099 